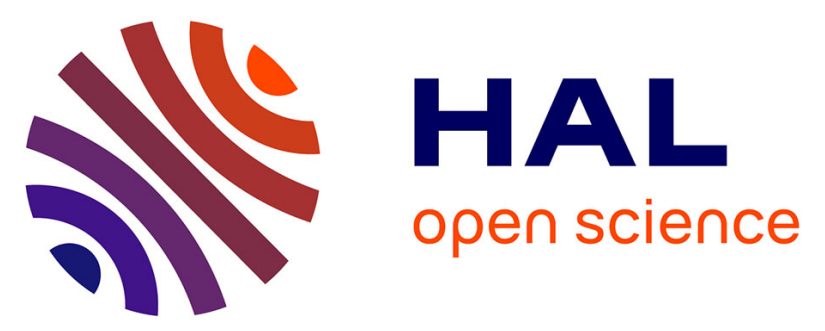

\title{
Numerical Study of Perturbators Influence on Heat Transfer and Investigation of Collector Performance for a Micro-Combined Heat and Power System Application
} Jojomon Joseph, Michel Delanaye, Rabia Nacereddine, Andres Giraldo, Mehdi Rouabah, Jan G Korvink, Juergen Brandner

\section{To cite this version:}

Jojomon Joseph, Michel Delanaye, Rabia Nacereddine, Andres Giraldo, Mehdi Rouabah, et al.. Numerical Study of Perturbators Influence on Heat Transfer and Investigation of Collector Performance for a Micro-Combined Heat and Power System Application. Heat Transfer Engineering, 2020, 10.1080/01457632.2019.1707387 . hal-02446507

\section{HAL Id: hal-02446507 \\ https://hal.science/hal-02446507}

Submitted on 23 Jan 2020

HAL is a multi-disciplinary open access archive for the deposit and dissemination of scientific research documents, whether they are published or not. The documents may come from teaching and research institutions in France or abroad, or from public or private research centers.
L'archive ouverte pluridisciplinaire HAL, est destinée au dépôt et à la diffusion de documents scientifiques de niveau recherche, publiés ou non, émanant des établissements d'enseignement et de recherche français ou étrangers, des laboratoires publics ou privés. 


\section{Numerical Study of Perturbators Influence on Heat Transfer and Investigation of Collector Performance for a Micro-Combined Heat and Power System Application}

Jojomon Joseph, Michel Delanaye, Rabia Nacereddine, Andres Giraldo, Mehdi Rouabah, Jan G. Korvink \& Juergen J. Brandner

To cite this article: Jojomon Joseph, Michel Delanaye, Rabia Nacereddine, Andres Giraldo, Mehdi Rouabah, Jan G. Korvink \& Juergen J. Brandner (2020): Numerical Study of Perturbators Influence on Heat Transfer and Investigation of Collector Performance for a Micro-Combined Heat and Power System Application, Heat Transfer Engineering, DOI: 10.1080/01457632.2019.1707387

To link to this article: https://doi.org/10.1080/01457632.2019.1707387

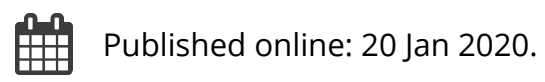

Submit your article to this journal $₫$

Q View related articles $\llbracket$

View Crossmark data 5 


\title{
Numerical Study of Perturbators Influence on Heat Transfer and Investigation of Collector Performance for a Micro-Combined Heat and Power System Application
}

\author{
Jojomon Joseph ${ }^{\mathrm{a}, \mathrm{b}}$, Michel Delanaye ${ }^{\mathrm{a}}$, Rabia Nacereddine ${ }^{\mathrm{a}}$, Andres Giraldo ${ }^{\mathrm{a}}$, Mehdi Rouabah $^{\mathrm{a}}$, \\ Jan G. Korvink ${ }^{\mathrm{b}}$, and Juergen J. Brandner ${ }^{\mathrm{b}}$ \\ ${ }^{a}$ Mitis, Liege, Belgium; ${ }^{b}$ Institute of Microstructure Technology, Karlsruhe Institute of Technology, Eggenstein-Leopoldshafen, Germany
}

\begin{abstract}
The objective of this article is to analyze complex micro-channels with wire-net and Sshaped perturbators and implement a reduced order modeling (ROM) approach to assess the entire heat exchanger performance and validate through experiments. Shifting the critical Reynolds number to lower values using perturbators decreases the pressure losses and enhance the thermal efficiency. There is an optimum mass flow (for both perturbators) where the thermal efficiency reaches maximum. The thermal efficiency of the wire-net perturbator is relatively high compared to S-shaped perturbators. The S-shaped perturbators induces strong wall-normal velocity fluctuations and enhances the heat transfer. Furthermore, the turbulence production term provides a deeper insight into flow attachment and detachment near the wire net intersections. The computational fluid dynamics approach (conjugate heat transfer models and ROM) was introduced to reduce the computational grid size and predict the collector performance. The secondary collector performance is determined by considering the microchannels as porous mediums. Apparently, the primary collector performance is determined by considering both secondary collectors and microchannels as porous mediums. The cylindrical secondary collectors contribute nearly $40-50 \%$ of the pressure drop. Experimental validation showed that the ROM predicts the heat exchanger performance with a good $(<4.4 \%)$ accuracy.
\end{abstract}

\section{Introduction}

The current global energy market is looking for different alternative resources to produce both electricity and heat simultaneously that are more efficient and environmentally friendly. Combined Heat and Power (CHP) produces energy from a single energy source, both heat and electricity concurrently [1]. A local micro-CHP intensifies the conventional centralized energy production (electricity and heat) from $60 \%$ to $90 \%$ [2] by reducing the heat losses during production and transport. The micro-CHP system based on a gas turbine system consists of a flameless combustion chamber, compressor, turbines, heat recovery system, and an electrical converter. Flameless combustion mode provides high combustion efficiency with low pollutant emissions, even with high air preheating [3]. Preheating doubles the electrical effectiveness of the unit while reducing the amount of heat recoverable as well as reduces the amount of injected fuel [4] for the micro-CHP system. Based on the present market studies, the target for thermal effectiveness must be higher than $85 \%$, and pressure losses must be less than $5 \%$ [5]. The primary objective of this article is to investigate the microchannel (with wire-net \& S-shaped perturbators) and collector (with wire-net perturbators) influence on Compact Heat Exchanger (CHE) performance for micro-CHP application.

The ratio of the heat transfer surface area of a heat exchanger to its volume is called the area density. Based on surface compactness, a CHE is having an area density greater than $700 \mathrm{~m}^{2} / \mathrm{m}^{3}$ and a hydraulic diameter less than $1 \mathrm{~mm}$ [6]. Increasing the area density increases the pressure drop and enhances the heat transfer. In rough pipes with smaller hydraulic diameter $(0.62$ and $1.032 \mathrm{~mm})$, turbulence transition occurs at low Reynolds number (less than Reynolds critical) [7].

CONTACT Jojomon Joseph Jojomon.joseph@partner.kit.edu $\mathrm{B}$ Karlsruhe Institute for Technology, Institute of Microstructure Technology, Hermannvon-Helmholtz-Platz 1, 76344 Eggenstein-Leopoldshafen, Germany.

Color versions of one or more of the figures in the article can be found online at www.tandfonline.com/uhte.

(C) 2020 Taylor \& Francis Group, LLC 


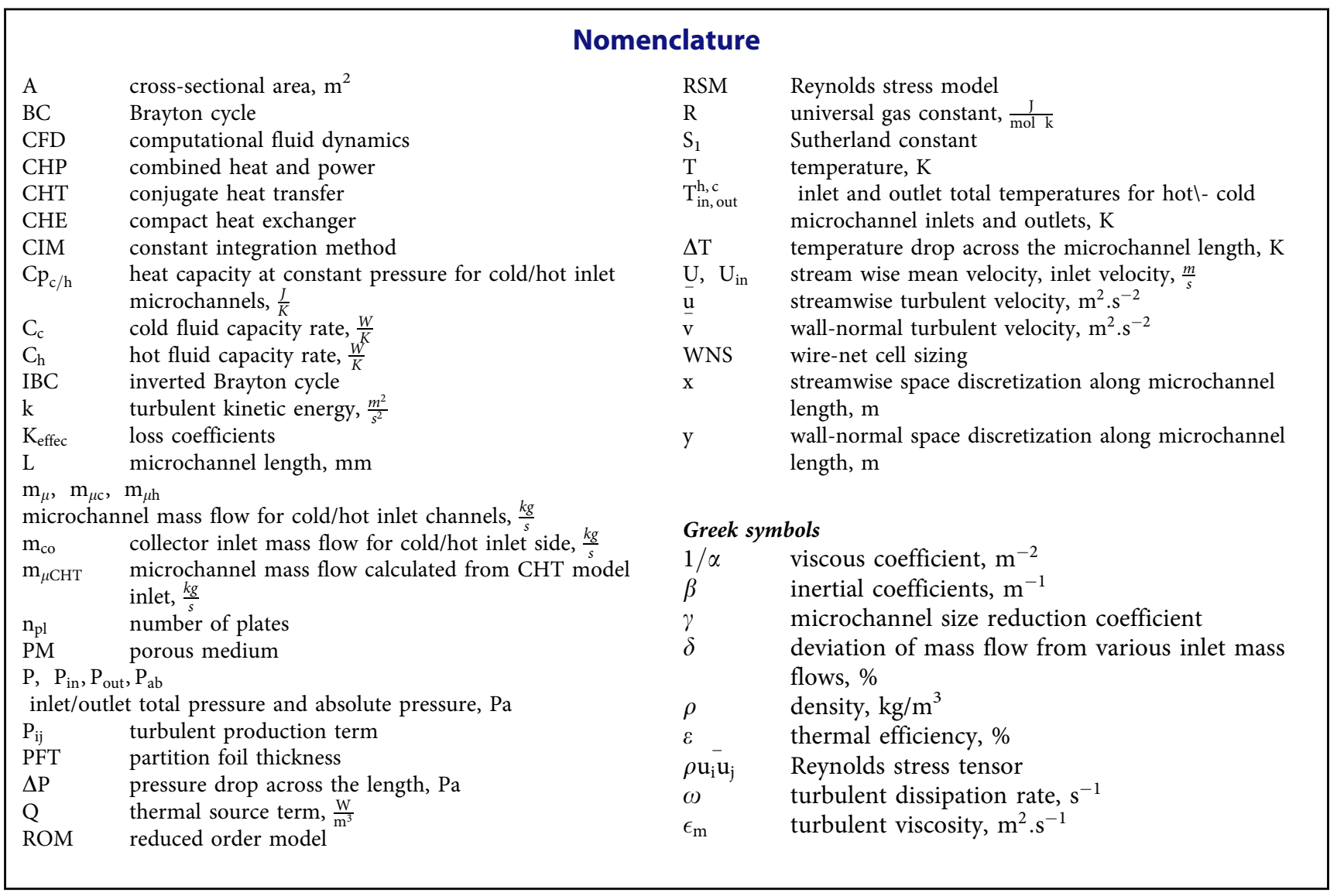

The effect of flow pattern influences the global heat transfer and pressure losses. The perturbators enhance the heat transfer by interrupting the viscous sublayer that leads to flow separation and smaller reattachment lengths [8]. High heat transfer and low-pressure losses occur along the flow reattachment and separation lines of leading-edge vortices [9]. However, areas of minimum convective heat transfer were found in regions of maximum turbulence production areas (coinciding with maximum Reynolds wall-normal stresses) due to high-velocity shear gradients. Thus, the maximum heat transfer coefficient occurred in the proximity of the reattachment points, where the wall shear stress is low, but the velocity fluctuations normal to the wall are high [10].

Transverse vortex generators and longitudinal vortex generators play a significant role in local and global heat transfer enhancements [11]. However, longitudinal vortex generators perturb the viscous sublayer along the flow direction and enhance the heat transfer as compared to transverse vortex generators [12]. The study made by Fiebig [13] revealed that counter-rotating vortex generators arrangements enhanced the heat transfer by more than twice that of the co-rotating configuration. Besides, he inferred that longitudinal vortices are remarkably persistent in both laminar and turbulent boundary layers and enhance the heat transfer locally and globally. Johnson and Joubert [14] made a study on the influence of longitudinal vortex on heat transfer and found that cylindrical drag was reduced due to separation delay caused by the longitudinal vortex enhanced the heat transfer.

The microchannel entrance length effects, as well as flow maldistributions [15] play an essential role in CHE performance. Studies made on different type of collectors' shapes showed that the creation of a stagnation zone, the growth of a boundary layer along the collector wall and low/high-velocity zones in the collector are the prime causes of flow maldistribution [16]. The partition foil thickness strongly influenced the CHE thermal effectiveness by affecting the axial conduction [17]. At the same time, the partition foils must withstand the stresses due to the pressure differences between counter-flow passages. At higher Reynolds numbers, the counter-flow configuration in a Plate CHE tends to give similar results to the crossflow arrangement due to cross-flow pattern that emerges due to the offset collector inlets and outlets [18].

Reduction in velocity flow gradients by changing the header shapes can decrease the maldistribution to 
a considerable extend [19]. Studies made on a quasiS-type header configuration showed that by extending the hydraulic path decreases the maldistribution and enhances the heat exchanger effectiveness, but with a low pressure loss as penalty [20]. For a parallel microchannel system, temperature distribution effect on flow maldistribution was investigated by Siva et al. [21]. He figured out that the high heat flux or high heated areas induced a reduction in viscosity of the fluid resulting in higher flow maldistribution. Different type of collectors: inclined baffle, segmental baffle, standard helical baffle, and improved helical baffle was investigated by $\mathrm{Chu}$ et al. [22] to study the maldistribution. He found that the inlet collector with equi-different helical baffles was the best by comparing the maldistribution, the Nusselt number, and the drag. Studies made by Li et al. [23] analyzed the performance of a conventional collector and recommended to use a baffle with small holes of three different kinds of diameters installed in the collector to enhance the flow maldistribution. Numerical studies were carried out by Dharaiya and Kandlikar [24] and Tong et al. [25] found that tapered collector configuration exhibit less flow maldistribution in microchannels. The flow distribution along the cylindrical straight collectors were non-uniform since the pressure along the inlet header is increasing and that along the outlet header is decreasing, resulting in flow maldistribution. However, the pressure along the inlet, as well as the outlet headers were found to be decreasing for the tapered configuration, which resulted in a better flow distribution through the channels. An experimental study conducted by Hoffmann et al. [26] measured the flow maldistribution on the hydraulic resistance of heat exchanger and concluded that the flow maldistribution in the axial direction increased anisotropic resistance.

It is complicated to validate the experimental predictions with Computational Fluid Dynamics (CFD) due to entrance and exit effects, differences in surface roughness in the different microchannels investigated, non-uniformity of channel dimensions, thermal and flow boundary conditions, and uncertainties and errors in instrumentation and measurements [27]. The porous medium based CFD methodology has been implemented by Barbaros et al. [28] for vehicle radiators with a temperature drop of approximately $323 \mathrm{~K}$. They used the standard porous medium approach by using a non-equilibrium heat transfer model, and the results were $\pm 15 \%$ accurate relative to experiments. A similar porous medium approach was introduced by Zhang [29] for a cross-flow air-air heat exchanger with plate-fin cores. His experimental results were in close agreement with the CFD model. However, the temperature drop was relatively small. Besides, Wang et al. [30] in his studies used a porous medium approach by disregarding the temperature. Joseph et al. [31] developed a new methodology based on the porous medium approach by modifying the DarcyForschmiers law to calculate inertial and viscous coefficients for significant temperature variations $(\Delta \mathrm{T}=750)$. The new methodology assessed the heat exchanger performance with reasonable accuracy $(<5 \%)$. In this article, we will use the same approach to investigate primary and secondary collector performance.

\section{Design}

The counter-flow gas-gas (air-air) compact heat exchanger (see Figure 1a) arrangement is a hybrid version of mesh and plate heat-exchanger arrangement. The CHE is assembled as a stack of counterflow passages separated by thin partition foils. Frames delimit the flow passages with integrated collectors. Geometries of both frames are identical, and they are positioned on top of each other by mirroring, which is shown in Figure 1 (patent number: WO 20161124472). A metallic wire net is inserted into the flow passages to provide the required thickness and stiffness for the CHE [32]. The wire-net was also replaced by S-shaped fins with appropriate spacing and orientation to compare it with the wirenet model.

Micro-CHP components are designed based on inverted Brayton (IBC), and Brayton cycles (BC) and the operating conditions are shown in Table 1. In order to decrease the numerical complexity, a standard atmospheric operating condition is implemented for higher-order turbulent simulations in both IBC and $\mathrm{BC}$ operating conditions, the $\mathrm{CHE}$ must withstand the stress-induced due to the pressure and the temperature differences. From the design point of view, the perturbators have a dual purpose. The main purpose is to support the thin partition foil (100-300 microns) at different operating conditions. The second purpose is to induce localized flow mixing.

\section{Wire-net model}

\section{Microchannels}

An arrangement of partition foils one above another results in counter-flow CHE with microchannels (see Figure 1). The partition foils are separated by wire- 


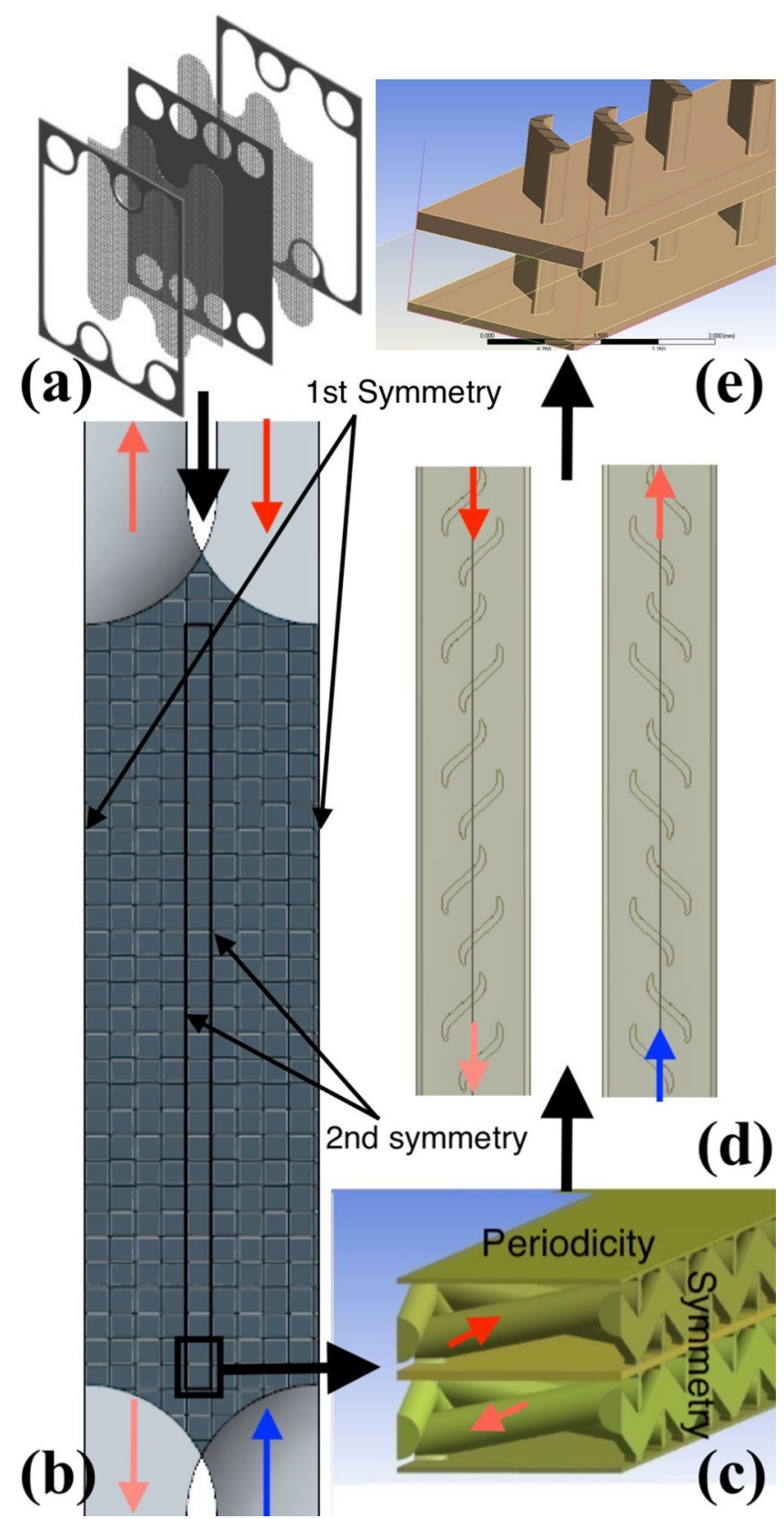

Figure 1. Heat exchanger arrangement (a), Primary symmetrical computation domain (b), secondary symmetrical computation domain-CHT model (c), Microchannels with S-shaped fins (d), and S-shape CHT model (e).

net structures that prevent buckling of thin partition foils and also ensure localized laminar/turbulent mixing and thereby enhances heat transfer at higher mass flow regimes. The foil thickness is selected to ensure low axial conduction while ensuring durability. When the frame thickness/hydraulic diameter decreases, the pressure drop inside the microchannels increases, but leading to structurally compact thermally efficient microchannels. The woolen weave Dutch type wire net is shown in Figure 1a-c.
Table 1. BC and IBC operating conditions for lower order turbulence models and normal operating conditions for higher order turbulence models.

\begin{tabular}{lcc}
\hline Case-BC & Temperature $(\mathrm{K})$ & Pressure (Bar) \\
\hline $\begin{array}{l}\text { Hot-inlet side } \\
\text { Cold-inlet side }\end{array}$ & 1,054 & 1 \\
Case-IBC & 407 & 3 \\
Hot-inlet side & 1,054 & 0.4 \\
Cold-inlet side & 298 & 1 \\
Normal/Standard & & \\
$\quad$ Hot-inlet side & 1,054 & 1 \\
Cold-inlet side & 298 & 1 \\
\hline
\end{tabular}

\section{Collectors}

Secondary collectors play a vital role in compact heat exchanger performance. The secondary cylindrical collector is integrated with each block of the compact heat exchanger as shown in Figure 1a. We consider an analysis of a single block of a compact heat exchanger, consisting of alternately brazed hot and cold channels. The microchannel efficiency and pressure losses are directly associated with the microchannel inlet mass flows and the flow maldistribution. The Reynolds number based on secondary collector and primary collector inlet is in the realm of $4,000-10,000$ and $15,000-50,000$, respectively.

\section{S-shape model}

The S-shaped fins were introduced to replace the wire net in order to reduce the high-pressure losses (see Figure $1 \mathrm{~d}, \mathrm{e})$. The fin shape influence on heat transfer and pressure losses were studied in detail by Tsuzuki et al. [33]. The fin angle was the most important parameter among the five selected parameters. In this article, we focus on different types of fin arrangements (with the optimum fin angle) that influence the thermalhydraulic performance for several operating conditions.

\section{CFD methodology}

CFD methodology comprises of conjugate heat transfer (CHT) analysis for a microchannel section and reduced order modeling ( $\mathrm{ROM})$ to analyze the entire compact heat exchanger performance based on the collector performance. Joseph et al. [31] introduced a ROM approach based on porous medium approximation (based on Darcy-Forchheimer law) to investigate the secondary collector performance. This article used the same method to investigate the secondary collector performance and utilized the scalability of the ROM to investigate the primary collector performance. The developed model takes into account the temperature evolution, localized turbulence effects, 


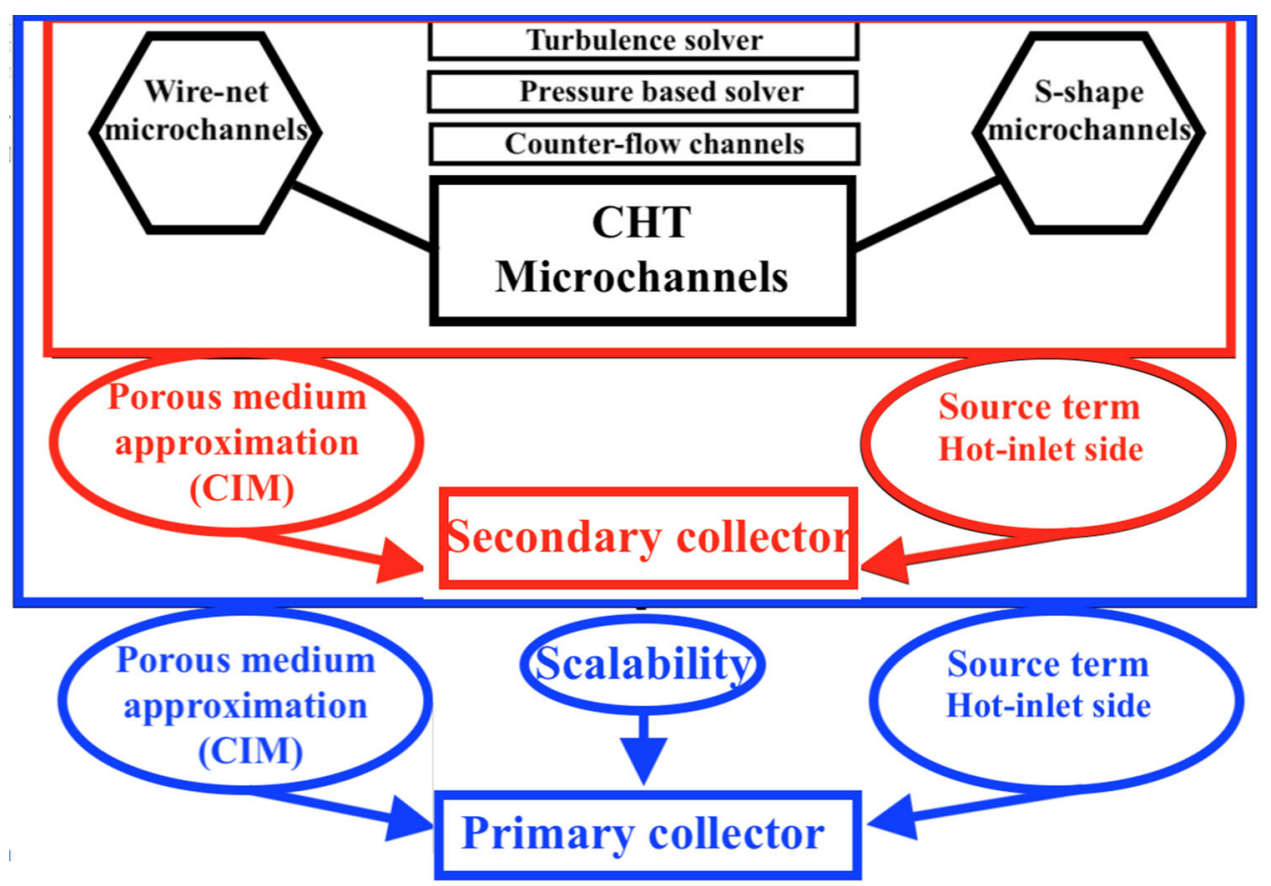

Figure 2. Numerical methodology.

and evaluates the porous medium characteristics. Rehman et al. [34] also used a similar approach to account for the compressibility effects (density), to model microchannel heat exchangers with high-pressure losses $(>15 \%)$. Both studies were validated numerically as well as experimentally.

The primary aim of the numerical study is to investigate in detail the microchannel flow physics and investigate the maldistribution effects caused by primary and secondary collectors and subsequent influence on overall thermal effectiveness and pressure losses. Overall thermal effectiveness is calculated based on flow-maldistribution, and pressure losses are deducted directly from the ROM. The microchannels of the wire-net/S-shape fins have a complicated structure, which makes the compact heat exchanger simulations computationally expensive. The best method is to split the CHE configuration part by part and analyze the performance using ROM. The modeling is estimated in three different stages:

- Microchannel CHT model - Estimating the microchannel performance using detailed three-dimensional CHT analysis.

- ROM for secondary collectors- Microchannels are replaced by porous medium models to evaluate the flow maldistribution and thereby the secondary collector performance. Therefore, the microchannels are having a very coarse mesh $(10,000$ cells per channels), and the secondary collector is having a highly refined mesh to capture the secondary effects.
- ROM for primary collectors- Scalability of the ROM is utilized to model both microchannel along with the secondary collectors as a single porous medium. Therefore, the effects of both microchannels and secondary collectors were introduced into a cylindrical duct. The cylindrical duct has a very coarse mesh, and the primary collector has a highly refined mesh. An overall heat exchanger performance is estimated based on the flow maldistribution and overall pressure losses.

A general scheme of the CFD methodology is depicted in Figure 2. Since the porous medium has a free-slip boundary condition, the computational domain is reduced. The collector's flow maldistribution influences the microchannels/secondary collectors' performance by creating an unbalanced flow in the counter-flow microchannels. When there is unbalanced mass flow, the heat transfer prediction is biased along with total pressure losses. The scalability of the ROM provides the easiness to create the temperature and pressure jump across different types of cross-sections. The overall thermal efficiency of the compact heat exchanger is determined from the mass flow-weighted average of each microchannel/collector thermal efficiency.

\section{Microchannel}

The compact heat exchanger assembly is illustrated in Figure 1. Two types of geometrical symmetry exist in a plane which is parallel to the inlet flow direction. The 
primary symmetrical domain (see Figure $1 b$ ) is along half of the secondary collector diameter, and the secondary symmetrical domain is at the center of the wire-net compact heat exchanger (see Figure 1c). It is computationally expensive to carry out a CHT analysis by holding the primary symmetry (see Figure 1b) [31]. Similarly, periodic boundary conditions were implemented in the plane that is perpendicular to the inlet flow direction. A periodicity exists in half of the microchannel foil thickness on every hot and cold side alternatively. Thus, all hot and cold microchannels were simplified into a single hot, and cold microchannels with partition foil above it, as shown in Figure 1c. The number of microchannels, together with the microchannel size reduction $(\gamma)$ coefficient, is utilized to calculate the microchannel inlet mass flow (see Eq. (1)) from the collector inlet mass flow.

$$
\mathrm{m}_{\mu}=\frac{\mathrm{m}_{\mathrm{co}}}{\gamma \mathrm{n}_{\mathrm{pl}}}
$$

The $\gamma$ coefficient is obtained from simplifying the computational domain with the help of symmetric and periodic boundary conditions. In conclusion, the primary symmetry is used for CHT analysis, and the secondary symmetry was implemented for the ROM.

The microchannel thermal efficiency, $\varepsilon, \%$ is calculated using the relation,

$$
\begin{gathered}
\varepsilon, \%=\frac{\mathrm{C}_{\mathrm{h}}\left(\mathrm{T}_{\text {in }}^{\mathrm{h}}-\mathrm{T}_{\text {out }}^{\mathrm{h}}\right)}{\min \left(\mathrm{C}_{\mathrm{c}}, \mathrm{C}_{\mathrm{h}}\right)\left(\mathrm{T}_{\mathrm{in}}^{\mathrm{h}}-\mathrm{T}_{\mathrm{in}}^{\mathrm{c}}\right)} \times 100 \\
\mathrm{C}_{\mathrm{c}}=\mathrm{m}_{\mu \mathrm{c}} \mathrm{Cp}_{\mathrm{c}} ; \mathrm{C}_{\mathrm{h}}=\mathrm{m}_{\mu \mathrm{h}} \mathrm{Cp}_{\mathrm{h}}
\end{gathered}
$$

With $\mathrm{Cp}_{c, h}$ being the hot and cold fluid capacity rates. $\mathrm{T}_{\mathrm{in} \text {, out }}^{\mathrm{h}}$ and $\mathrm{T}_{\mathrm{in} \text {, out }}^{\mathrm{c}}$ are the inlet and outlet temperatures of the counter-flow channels. The microchannel pressure losses, $\Delta \mathrm{P}, \%$ were calculated using the relation,

$$
\Delta \mathrm{P}, \%=\frac{\mathrm{P}_{\text {in }}-\mathrm{P}_{\text {out }}}{\mathrm{P}_{\mathrm{ab}}} \times 100
$$

\section{Secondary collectors}

Due to the complex geometry of the microchannels, it is numerically expensive to undergo a full $\mathrm{CHT}$ analysis for the cylindrical secondary collectors. The porous medium approach proposed by Joseph et al. [32] reduced the computational mesh size and solver complexities to a considerable extent (400 million to 10 million). The global characteristics of the $\mathrm{CHT}$ analysis is utilized to calculate the inertial and viscous coefficients (porous medium model) of the ROM using a Constant Integration Method (CIM) [32]. The Darcy-Forchheimer law was modified and implemented to account for the temperature variation and localized turbulence effect. CIM was introduced to calculate the inertial and viscous coefficients accurately as a function of the mass flow rate,

$$
\begin{aligned}
& \frac{\Delta\left(\mathrm{P}_{\text {in }}-\mathrm{P}_{\text {out }}\right)}{\mathrm{L}}=\frac{1}{\alpha} \frac{\mathrm{L}}{\Delta \mathrm{T}} \frac{\mathrm{m}_{\mu}}{\mathrm{A}} \frac{\mathrm{R}}{\mathrm{P}}\left[\left[\mathrm{T}^{0.5}\left(3 \mathrm{~T}^{2}-5 \mathrm{~S}_{1} \mathrm{~T}+15 \mathrm{~S}_{1}^{2}\right)\right.\right. \\
& \left.\left.-15 \mathrm{~S}_{1}^{2.5} \arctan \left(\frac{\mathrm{T}^{0.5}}{\mathrm{~S}_{1}^{0.5}}\right)+\epsilon_{\mathrm{m}} \frac{\mathrm{PT}}{\mathrm{R}}\right]_{\mathrm{T}_{\text {in }}}^{\mathrm{T}_{\text {out }}}+\frac{1}{2} \beta \frac{\mathrm{m}_{\mu}}{\mathrm{A}}\left[\frac{\mathrm{T}^{2}}{2}\right]_{\mathrm{T}_{\text {in }}}^{\mathrm{T}_{\text {out }}}\right]
\end{aligned}
$$

In the above Eq. (5), all the parameters other than the two unknown coefficients, inertial $(\beta)$ and viscous coefficients $(1 / \alpha)$ of the linearized equation is calculated from the microchannel CHT model. Solving the linearized equation (Eq. (5)) for different mass flows results in inertial and viscous coefficients that vary based on mass flow.

The temperature variation between the hot and cold inlets of the microchannel is $750 \mathrm{~K}$, which brings density variations in the flow. Based on the mass flow, the source term provides temperature variation in the ROM. Mesh model of the secondary collector with 60 microchannels (as porous mediums) is depicted in Figure 3a. Power per unit volume was implemented as a source term along the microchannels (see Eq. (6)) Joseph et al. [32] implemented the new approach and validated the porous media model (with modified inertial and viscous coefficients) for secondary collectors.

$$
\mathrm{Q}=\mathrm{m}_{\mu \mathrm{CHT}}\left(\mathrm{T}_{\mathrm{in}}^{\mathrm{h} / \mathrm{c}}-\mathrm{T}_{\mathrm{out}}^{\mathrm{h} / \mathrm{c}}\right) \mathrm{Cp}_{\mathrm{h} / \mathrm{c}}
$$

An overall secondary collector efficiency (\%) is calculated as the mass flow-weighted average of all microchannels thermal efficiency and pressure loss is extracted directly from the CFD model with reducedorder modeling.

\section{Primary collectors}

In this article, trapezoidal shaped primary collectors are implemented to distribute and collect the mass flow from 16 secondary collectors to a single primary collector. The mesh model is portrayed in Figure 3b and it consists of 16 porous medium zones (PM1, PM2 ... PM16) with a single hot-inlet and outlet. The mesh was relatively very coarse $(30,000$ cells $)$ in the porous medium regimes. An overall CHE thermal efficiency is calculated as the mass flow weighted average of all the secondary collector performance (along with microchannels) and pressure drop is extracted directly from the CFD model with reduced-order modeling. 


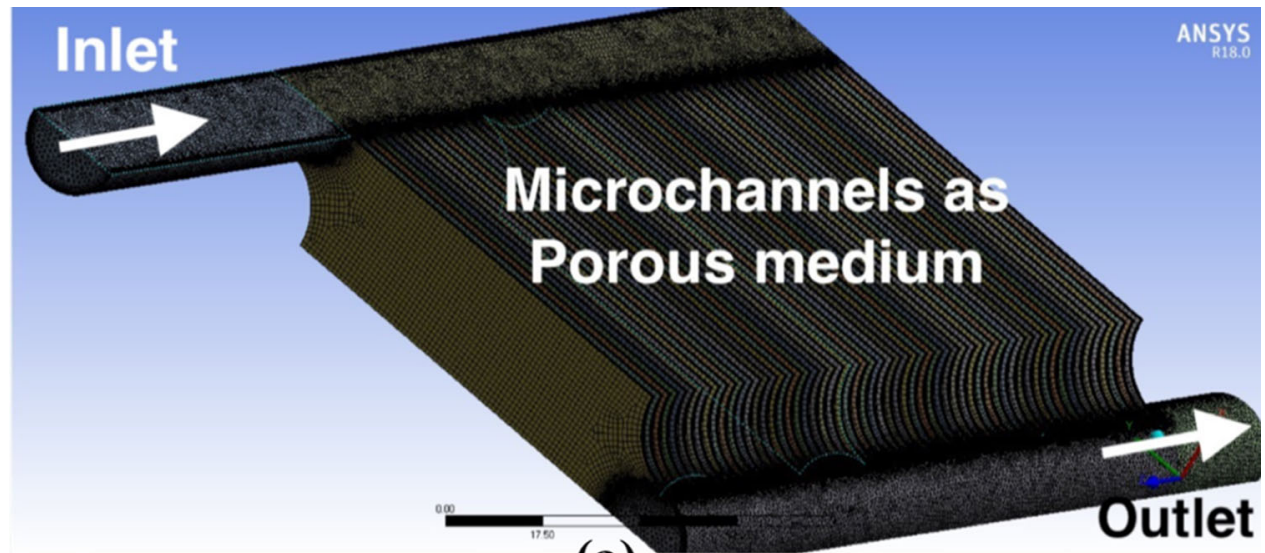

(a)

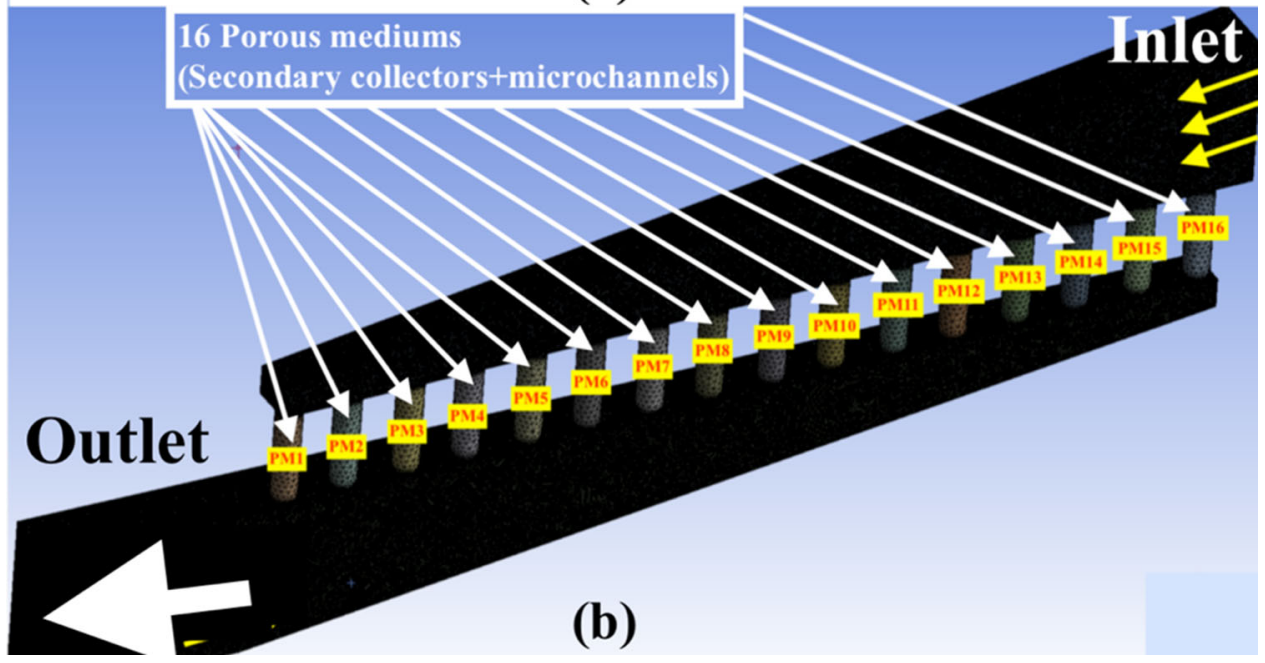

Figure 3. Mesh model for secondary collectors with 60 microchannels (a) and primary collector for 16 secondary collectors (along with microchannel effects) (b).

\section{Scalability of the reduced order model}

The scalability of the ROM is a significant feature required to investigate the performance of a primary collector. The primary objective is to validate the inertial and viscous coefficients (calculated using CIM) reproduces the same pressure drop for geometries with different cross-sections. The scalability of ROM helps to introduce pressure drop along with temperature drop across different cross-sectional shapes and lengths. In order to verify the scalability, the performance characteristic of 60 microchannels together with the secondary collectors were considered as a single porous medium with a circular cross-section. A free slip wall boundary condition along with a source term was implemented to introduce the temperature drop. A new source term is calculated using Eq. (6). Figure $4 \mathrm{a}, \mathrm{b}$, shows the mesh as well as the temperature distribution obtained across a single microchannel and also the cylindrical duct (which takes into account the temperature and pressure loss of 60 microchannels and secondary collectors). The mesh is relatively coarse and depicted in Figure $4 \mathrm{a}, \mathrm{b}$, and the temperature drop corresponds to the temperature drop of CHT models.

When the primary collector inlet mass flow/area is changed, a revised inertial and viscous coefficients were calculated using CIM as shown in Table 2. The pressure losses and thermal efficiency estimated from the secondary collector ROM is considered as the original model. The scaled model refers to the cylindrical channel that reproduces the performance of both secondary collectors and 60 microchannels. The secondary collector pressure drop and temperature drop were provided as an input for the CIM model to determine the inertial and viscous coefficients. The total pressure losses for the scaled model and the original model for various mass flows are depicted in Figure 4c. The difference between the pressure drop as well as the thermal efficiency for both scaled and the original model is less than $(<4 \%)$. Thus, the ROM is scaled and modified to bring the temperature drop and pressure losses of the secondary collector and microchannels to a simple cylindrical duct with a secondary collector diameter. 

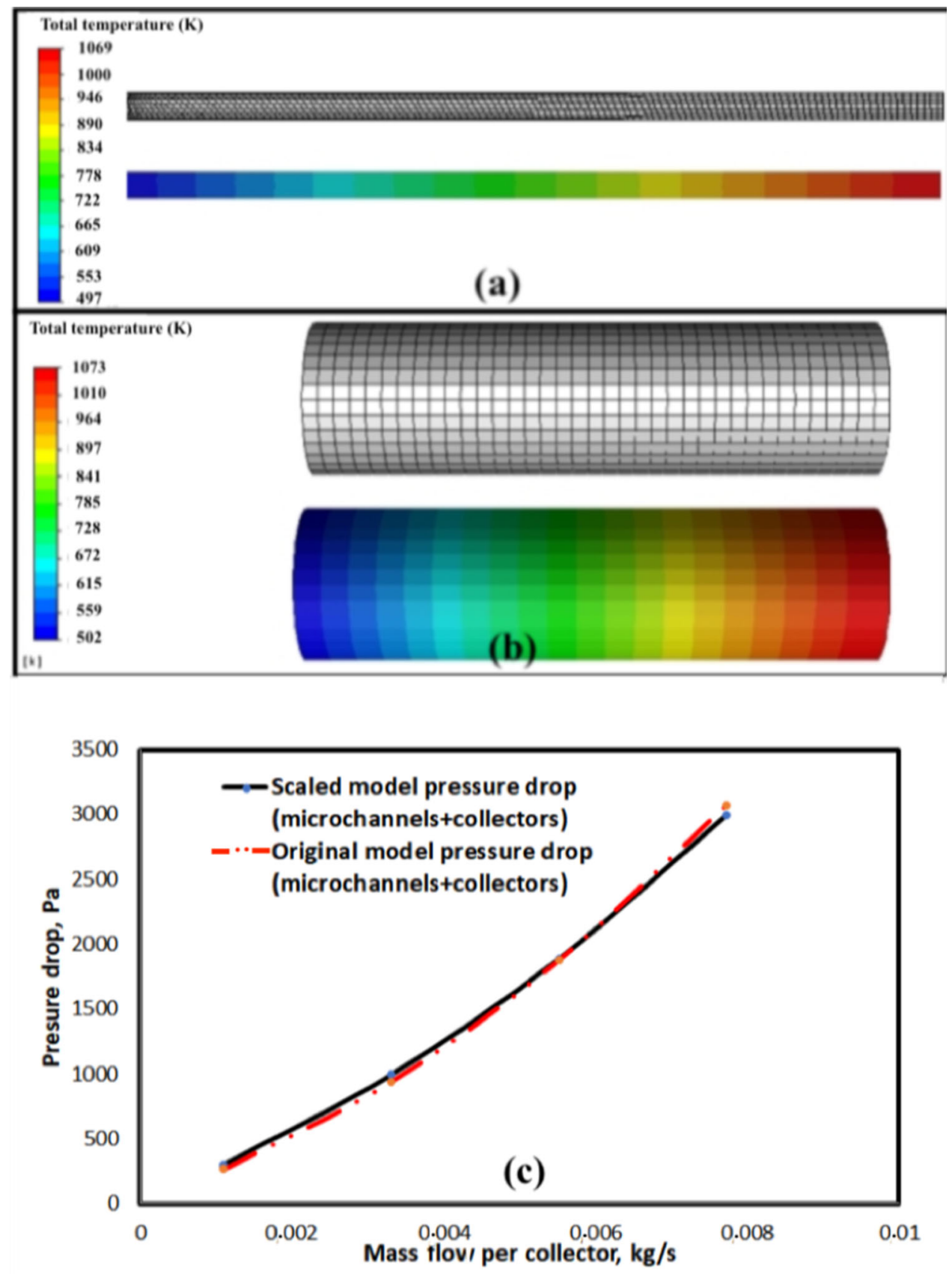

Figure 4. Wire-net mesh and temperature distribution for original model (a), scaled model (b), validation plot for original model, and scaled model (c).

\section{Results and discussion}

\section{Microchannels}

\section{Velocity distribution}

The primary symmetrical domain (see Figure $1 b$ ) is computationally expensive for a CHT analysis. On the contrary, the second symmetry assumption is computationally cheap. The objective of this particular analysis is to investigate the homogeneity in the wire-net flow physics and verify the second symmetry assumption for the CHT analysis. The CFD simulation was conducted
Table 2. Comparison between scaled model and original model.

\begin{tabular}{lcc}
\hline & Original model & Scaled model \\
\hline Inertial $(1 / \mathrm{m})$ & 87470000 & 12185000 \\
Viscous $\left(1 / \mathrm{m}^{2}\right)$ & 1745 & 33 \\
\hline
\end{tabular}

on the primary symmetrical domain using the commercial three-dimensional CFD code, FLUENT.19. To decrease the solver complexity, turbulent $\mathrm{k}-\omega$ shear stress transport turbulent model without energy equations were adopted for the preliminary study. 


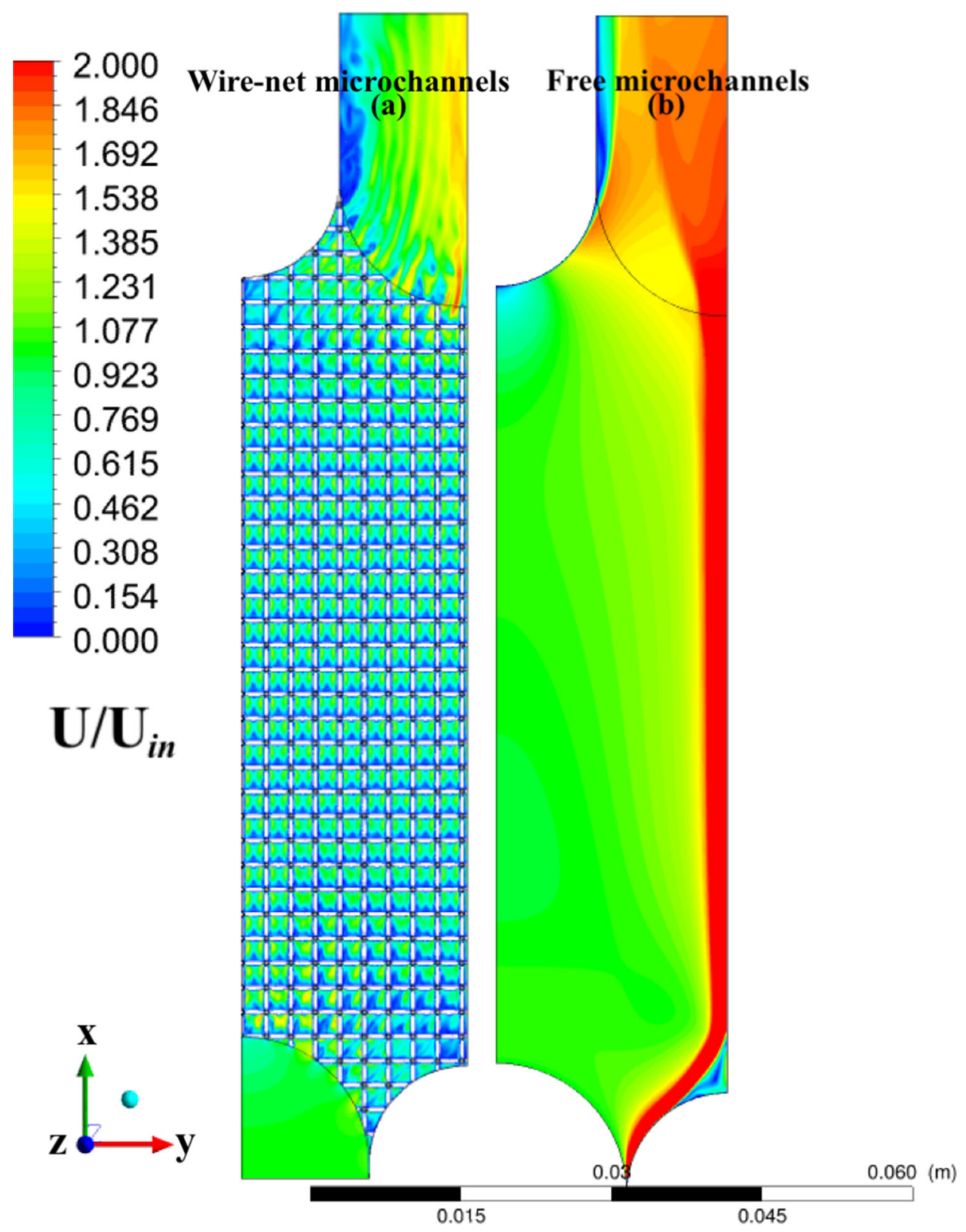

Figure 5. Non-dimensional velocity contour based on the primary symmetry.

Figure 5 shows the non-dimensionalized (inlet velocity) velocity distribution of microchannels with and without wire-net. The non-uniform velocity distribution in microchannels without wire-net adversely affects the CHE performance as mentioned by Yang et al. [20]. This is due to the least resistance from the inlet to the outlet. This diminishes the benefits of counter-flow passages since the maximum velocity gradients lie at two extreme inlets (see Figure 5b). However, the microchannels with wire-net have a homogeneous velocity distribution that retains the counter-flow effects (see Figure 5a). This is found similar to the conventional grid turbulence theory where a grid generates turbulence that is nearly homogeneous and isotropic, and this is the idealized model assumed in most of the turbulence theories $[35,36]$. In summary, the second symmetrical assumption can be utilized to analyze the wire-net microchannel performance by neglecting the first symmetry. This simplifies the computational domain to a very large extent for a wire-net model.

\section{Conjugate heat transfer analysis}

Three-dimensional, ideal gas, steady conjugate heat transfer simulations were carried out to investigate the effect of thermal efficiency and pressure losses for various inlet mass flows. The porosity due to the wire-net structures is approximately $83 \%$, which 


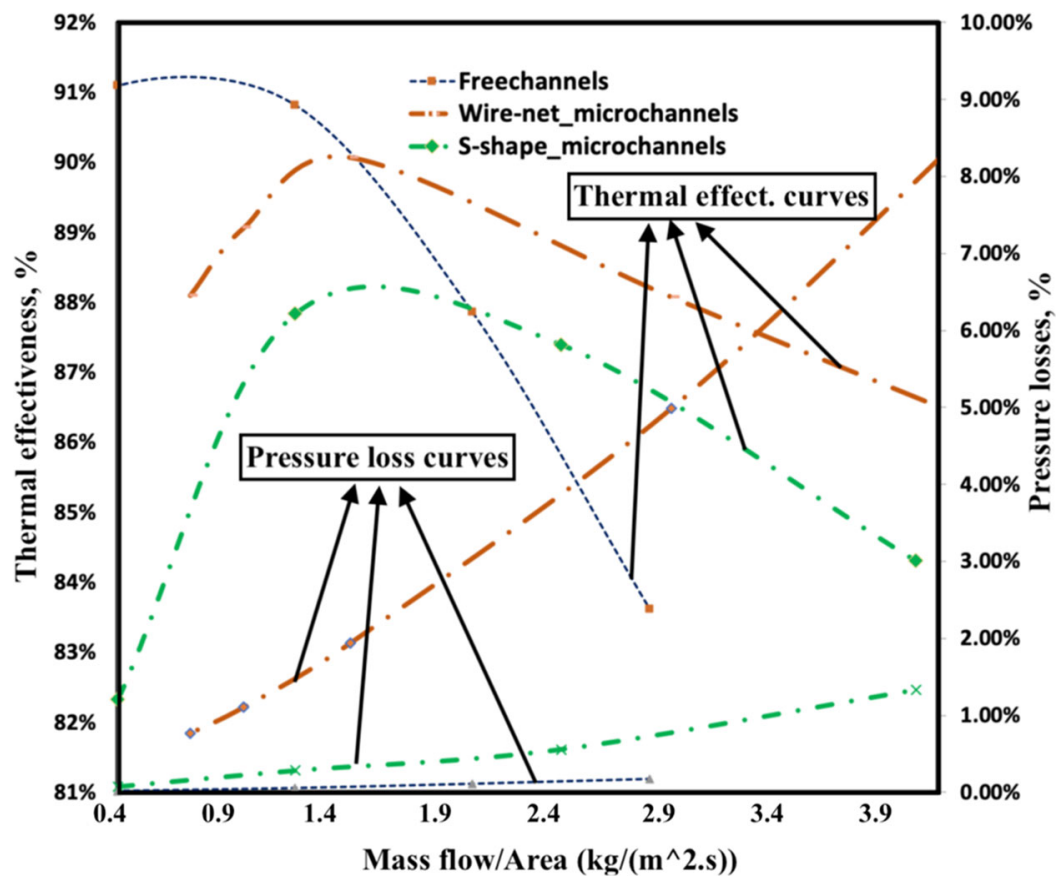

Figure 6. Pressure losses and thermal effectiveness for channels without perturbators, with S-shape and wire-net perturbators.

induces the transition to localized turbulence at low Reynolds number [32]. The CHT simulations were performed using the CFD solver FLUENT. For the velocity- pressure coupling, the SIMPLE algorithm has been implemented. The governing differential equations were discretized using a finite volume method on a polyhedral mesh with 12 to 14 million cells.

Figure 6 shows the thermal effectiveness (using Eq. (2)) and pressure losses (using Eq. (4)) for perturbators at different microchannel inlet mass flows. The microchannel entrance length for microchannels with perturbators is smaller (due to localized turbulence) as compared to free channels (laminar flow regime). There is an optimum mass flow where the thermal effectiveness reaches a maximum. For a CHT model, the hydrodynamic and thermal boundary layer will not be developed throughout the microchannel length due to different temperature drop at each location. In other words, the temperature or velocity gradients with respect to the length will not be zero at the center of the microchannel.

It is evident from Figure 6 that there is a thermal enhancement at a higher mass flow rate due to the perturbators (wire net/S-shaped fins) localized mixing. This increases the working range and thereby reduces the size and cost of the compact heat exchanger. From the design point of view, size and in turn costs are reduced by shifting the optimum working range to higher mass flows and flattening the efficiency curve at higher mass flow regimes.
The conventional quadratic increase in pressure losses based on microchannel inlet mass flow is evident from Figure 6. The wire-net structures have higher pressure losses as compared to the S-shaped fins and free channel (see Figure 6). Besides, the steepness of the thermal efficiency curve at lower mass flow is almost similar for all the test cases. The microchannels without perturbators (free channels) are steeper, which means less efficient. On the contrary, due to the flow mixing produced by the perturbators, the steepness of the thermal efficiency curve is relatively low. S-shape has lower pressure losses as compared to the wire-net. Thereby the compact heat exchanger becomes more compact and capable of recovering heat from the same total mass flow.

As mentioned before, the target pressure loss and thermal efficiencies are less than $5 \%$ and greater than $85 \%$, respectively. At mass flow/area equal to 3 , the relative difference (between wire-net and s- shape) in thermal efficiency is $1 \%$, while the relative difference (between wire-net and s-shape) in pressure loss is $4 \%$. In conclusion, S-shaped perturbators are better since both thermal effectiveness and pressure losses affect the micro-CHP performance in a linear manner. From the manufacturing point of view, the wire-net perturbators are more simple and effective in terms of manufacturing and maintaining good surface quality. On the other hand, s-shaped perturbators require advanced manufacturing techniques (chemical itching, 


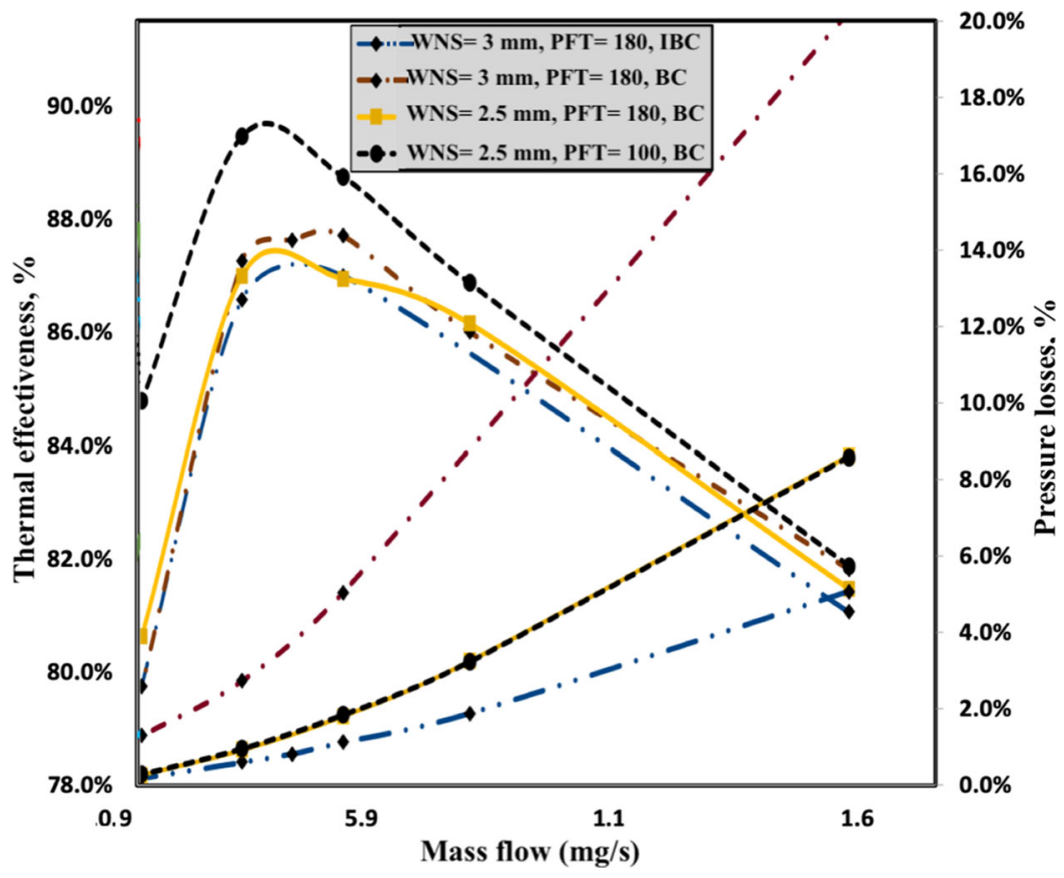

Figure 7. Pressure losses and thermal effectiveness for wire-net microchannels (parametric studies).

3D-printing, etc.) and it's difficult to maintain good surface quality.

\section{Parametric studies}

A parametric study was performed for a wide range of parameters, e.g., wire net cell size, microchannel operating conditions ( $\mathrm{IBC} / \mathrm{BC})$ and thickness of the partition foil. In this article, a square type wire net is used in which the opening size, longitudinal and diagonal size of the wire net remains constant, and altogether it is mentioned as Wire-Net Sizing (WNS). A parametric study was conducted for wire-net sizing $(2.5 \mathrm{~mm}$ and $3 \mathrm{~mm})$. From the structural analysis, it was observed that a further rise in WNS (from $3 \mathrm{~mm}$ ) could introduce buckling of the partition foils due to the pressure differences. Pressure loss is higher for the microchannels with smaller WNS $(2.5 \mathrm{~mm})$, and the pressure loss increases as the mass flow increases (see Figure 7). The lower wire-net sizing has slightly enhanced thermal efficiency. Regarding pressure losses, microchannels with IBC operating conditions generated more pressure losses relative to $\mathrm{BC}$ operating condition, which is due to the sub-atmospheric conditions on the hot inlet side. However, the thermal efficiency enhancement for both operating conditions almost remains the same.

The pressure losses variation was relatively low when the Partition Foil Thickness (PFT) was changed. However, PFT strongly influences the microchannel thermal efficiency (see Figure 7). As the PFT decreases, axial conduction also decreases improving heat transfer between the channels. On the other hand, thinner foils may affect the life of the CHE because of high-temperature oxidation and corrosion. Besides, as the PFT decreases, oxidation becomes a major limiting factor for its service life [37]. The operating condition (BC and IBC) introduces buckling of the thin partition foils.

Another parametric study was also conducted for microchannels with S-shaped fins for the same microchannel length. The number for S-shaped fins for normal, inverted and aligned configurations were 22, 26, and 26, respectively. Figure 8 shows the pressure loss and thermal efficiency of the microchannels with different S-shaped fin arrangement. The quadratic pressure loss curve is directly plotted along the secondary $y$-axis, and the thermal efficiency is plotted along the primary y-axis. The microchannel performance is not directly proportional to the number of fins. However, the performance is directly proportional to the flow physics, which will be discussed in the following section. Globally, the pressure losses were lowest for the case in which the S-shaped fins were inverted, which results in lower thermal efficiency as well.

\section{Turbulence production on heat transfer enhancement}

Besides, a detailed investigation of the wire net and sshape flow physics is analyzed using a higher order Reynolds Stress model (RSM). This was carried out to obtain the full velocity gradient tensor and investigate the anisotropic flow physics for both perturbators. 


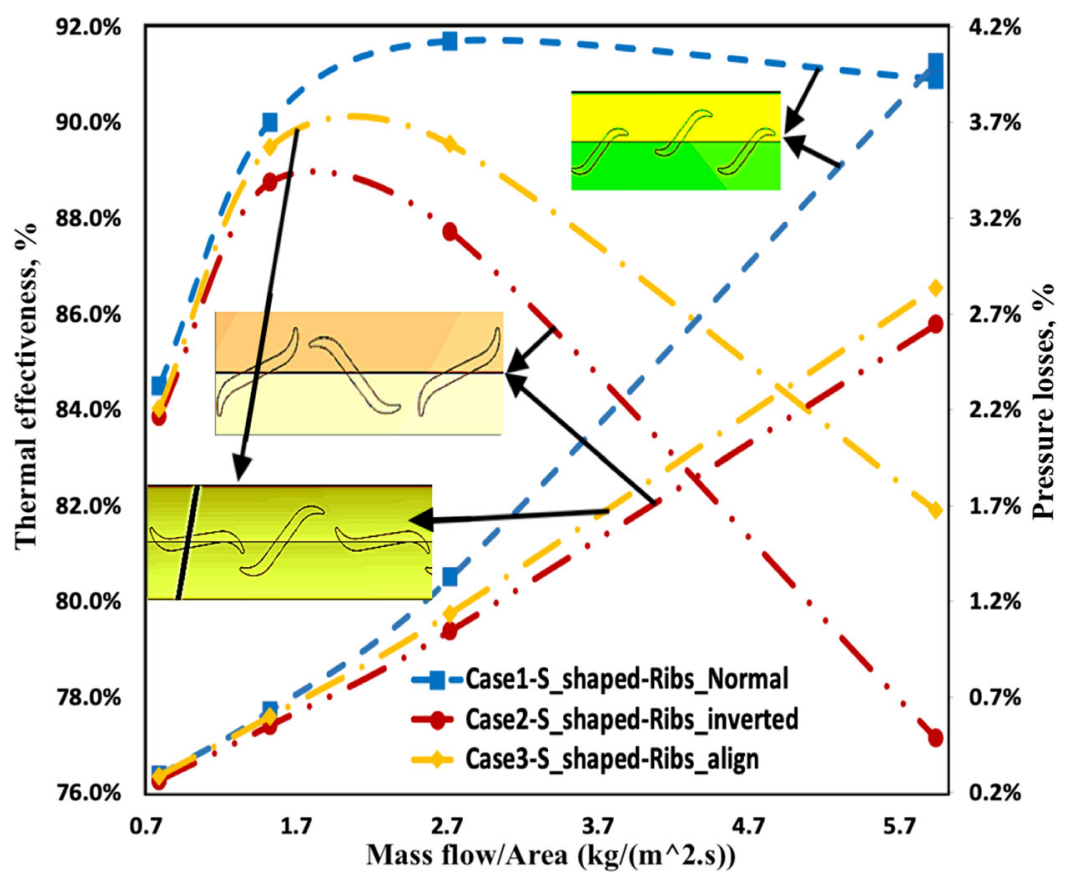

Figure 8. Pressure losses and thermal effectiveness for S-shape microchannels (parametric studies).

The mesh for the RSM model was highly refined at proximities and curvatures to capture any sharp gradients. Normal operating conditions (see Table 1) were used to decrease the solver complexity.

Wire-net: Higher order RSM calculates all the turbulent Reynolds stress terms $\left({\overline{\mathrm{u}_{i} \mathrm{u}_{\mathrm{j}}}}\right)$ by solving the stress transport equation [38]. Turbulent kinetic energy production is dominant after the circular cross-section, which is due to the localized mixing of wire-net cross- sectional structures. Among the three normal stresses, wall normal stress appears to be dominant $(>75 \%)$ as seen in Figure 9 which shows an enhanced mixing of centrally convected fluids and also an increased pressure loss. Due to the large velocity shear gradients, the peaks of the Reynolds wall normal stresses (see Figure 9b) coincided with maximum turbulence production areas (see Figure 9a), which is coherent with the observations made by Meinders et al. [39]. As a result, the major share of the localized turbulence induced by the wire net enhanced the heat transfer rather than just increasing the pressure losses. The strong wall-normal velocity fluctuations are produced by the wire net cross- sectional structures together with the near wall regions of partition foils, this takes energy from the streamwise velocity and damps the energy to the walls thereby enhancing heat transfer. In particular, turbulent production terms do not require modeling in RSM since they only involve moments of order less or equal to two [40]:

$$
\mathrm{P}_{\mathrm{ij}}=\rho \overline{\mathrm{u}_{\mathrm{i}} \mathrm{u}_{\mathrm{k}}} \frac{\partial \mathrm{U}_{\mathrm{i}}}{\partial \mathrm{x}_{\mathrm{k}}}-\rho \overline{\mathrm{u}_{\mathrm{j}} \mathrm{u}_{\mathrm{k}}} \frac{\partial \mathrm{U}_{\mathrm{j}}}{\partial \mathrm{x}_{\mathrm{k}}}
$$

In RSM, turbulence production terms are not modeled. Influence of the wire net intersections is evident from one among the turbulence production term, $\rho \overline{\mathrm{uv}} \mathrm{dU} / \mathrm{dx}$ extracted from Eq. (7). The stream wise mean velocity gradient, $\mathrm{dU} / \mathrm{dx}$ is supposed to be positive and negative before and after the circular cross-section due to strong favorable and adverse pressure gradient zones [41]. The $\rho \overline{\mathrm{uv}}$, vertical flux of stream wise momentum produced by the wire net walls suppress these strong flow detachment/separation zones behind the cylindrical cross-sections (see Figure 9c). This separation is suppressed by the nearby wire-net cross-sectional.

S-shape: The normal configuration is having the maximum thermal efficiency, while the inverted configuration has the minimum thermal efficiency. Also, the pressure loss is lower for an inverted configuration (see Figure 8). Both configurations were chosen for RSM analysis. Figure $9 \mathrm{~d}-\mathrm{f}$ shows the wall normal turbulent Reynolds stress, wall heat flux and turbulent production term $(\rho \overline{\mathrm{uv}} \partial \mathrm{U} / \partial \mathrm{y})$, respectively. The flow separation is initiated near the tip of the fins and suppressed by the following s-shape fin. The wall heat flux is improved at the center of the shear zones, which originates from separation phenomena. The wall normal turbulent stresses coincided with the maximum wall heat flux. The turbulent production term determine the 


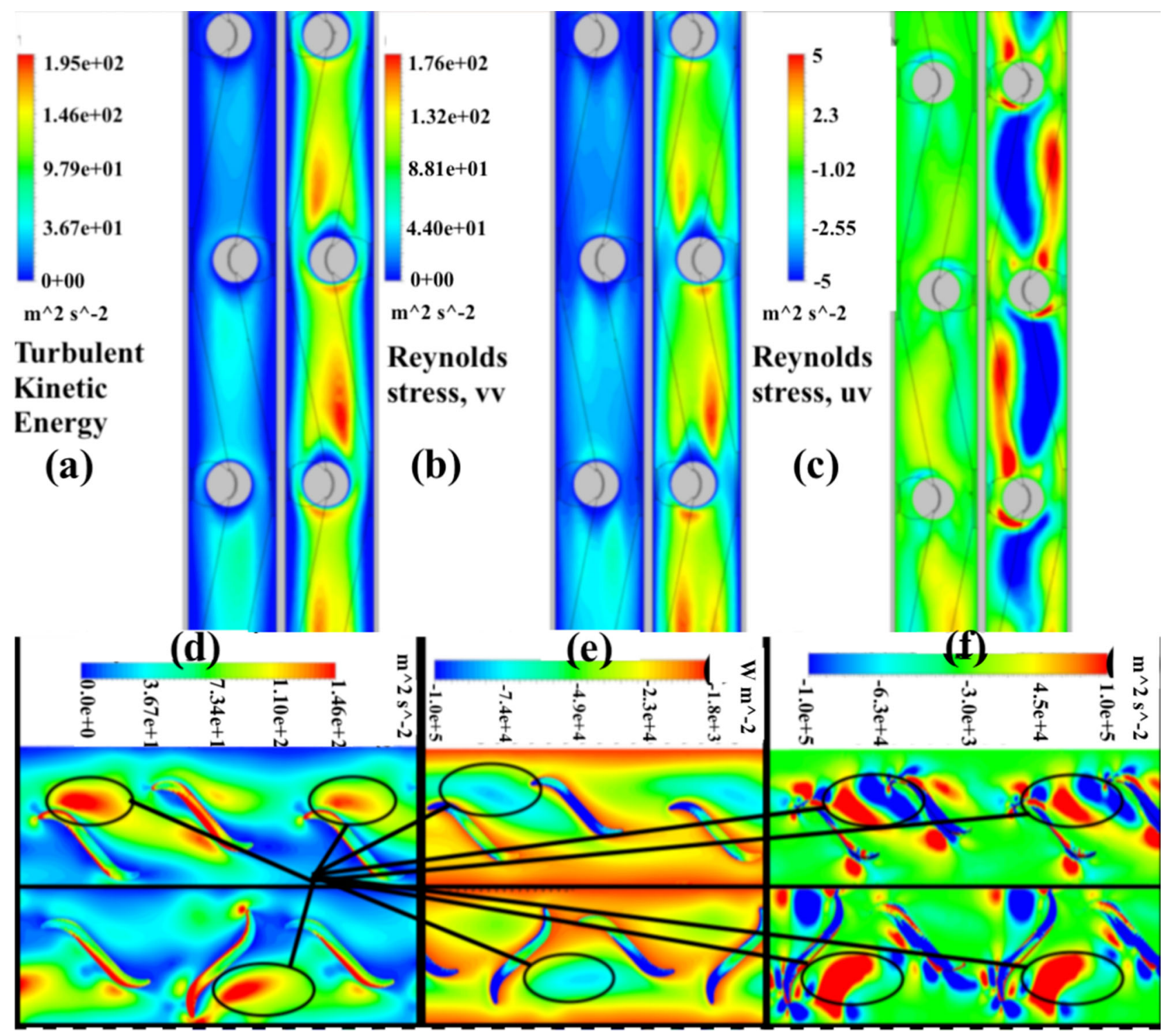

Figure 9. Turbulent kinetic energy for wire-net (a), turbulent wall-normal Reynolds stress for wire-net (b), Reynolds stress for wirenet (c), turbulent wall-normal Reynolds stress for S-shape (d), wall heat flux for S-shape (e), and turbulent production term for Sshape (f).

work of deformation of the mean motion by the turbulence stresses per unit volume per unit time [42]. When the correlation $(\rho \overline{\mathrm{uv}} \partial \mathrm{U} / \partial \mathrm{y})$ is maximum, it shows the influence of mean velocities momentum degradation by turbulent Reynolds stresses. $\rho \overline{\mathrm{uv}} \partial \mathrm{U} / \partial \mathrm{y}$ is higher for normal configuration. The positive and negative turbulence production corresponds to the sweep, ejection, outward interaction, and inward interaction phenomena (Quadrant analysis [43]).

The screening effect of one fin on another is relatively low for normal s-shaped fin arrangement (see Figure $9 \mathrm{~d}-\mathrm{f}$ ). The flow separation is strong for normal configuration. There is a small flow detachment for the inverted configuration. From the vorticity study, it was found that there is a strong small vortex that originates at the tip of the inverted S-shaped arrangement, results in flow detachment and thereby the turbulence production term is entirely positive. The turbulence production on/near S-shaped fins can be neglected since the contribution of thick S-shape perturbators toward heat transfer is relatively low (compared to partition foils). The turbulence production is maximum (both positive and negative) for normal configuration (with the highest thermal efficiency) and minimum (totally positive) for the inverted configuration with minimum thermal efficiency. In conclusion, the relative pressure losses for the S-shape perturbator is lower (see Figure 6), and the turbulence contribution is mainly to enhance the heat transfer (compared to wire-net). 


\section{Collector performance}

Collector pressure losses along with mass flow distribution, play a vital role in the CHE performance. It is crucial to ensure microchannels working at their optimum mass flow regime. Apparently, the wire-net is computationally expensive (relative to S-shape) with intricate flow patterns. Microchannel porous medium characteristics for both primary and secondary collectors were based on wire-net perturbators.

\section{Secondary collector performance}

The global parameters such as pressure drop, thermal efficiency and turbulent viscosity were determined from 3D CHT analysis and is utilized to compute the inertial and viscous coefficients using a constant integration method for a series of mass flows. Source term implementation provides a uniform temperature distribution along the microchannel. Thus, all microchannels were replaced by the porous media model (inertial and viscous coefficients calculated using the constant integration method) along with the source term implementation. Each microchannel mesh size is coarse $(10,000$ cells $)$ as compared to the CHT mesh model $(10 \mathrm{E}+7$ cells), to mimic the microchannel characteristics. Both collectors were highly refined to capture the microchannel entrance effects, stagnation zones, the boundary layer growth along the collector wall and low/high-velocity zones.

Velocity contour: Inertial and viscous coefficients were calculated using the constant integration method for microchannels without wire net (No-slip walls) and microchannels with wire-net. A single cylindrical collector inlet mass flow with free slip walls on 60 microchannels. Figure 10a,b show the velocity contours in the central plane for microchannels with and without wire- net respectively. An active recirculation zone, present in the collector beds influences the mass flow distribution, which will be considered in the following section. As the microchannel pressure loss increases, the recirculation strength in the collectors becomes more active. Since the free microchannels have the least resistance, the intensity of the recirculation zone is relatively small. Teng et al. [44] in his studies showed that as the flow resistance in the microchannel increases, the maldistribution is relatively less.

Mass flow distribution: The mass flow deviation from the CHT inlet mass flow is depicted in Figure 10c. The mass flow deviation is calculated using,

$$
\delta, \%=\frac{\mathrm{m}_{\mu \mathrm{CHT}}-\mathrm{m}_{\mu}}{\mathrm{m}_{\mu}} \times 100
$$

$\delta$ is the deviation for various secondary collector inlet mass flows, $\left(\mathrm{m}_{\mu \mathrm{CHT}}\right)$ for each of the microchannel porous medium models. $\mathrm{m}_{\mu}$ is the microchannel mass flow calculated from the ROM. The mass flow distribution near the collector beds become irregular and deviation from the estimated CHT mass flow increases which is due to the intense recirculation zones that is evident from the velocity contour. As the mass flow decreases, the microchannel pressure losses decreases and the non-uniformity in the collector flow distribution increases, especially near the collector beds. Overall thermal efficiency and pressure losses calculated using ROM for $\mathrm{BC}$ operating conditions is shown in Table 3.

\section{Primary collector performance}

A single hot-inlet side and cold-outlet which distribute the primary collector mass flow to 16 different cylindrical channels were chosen from the preliminary investigation. The 16 cylindrical channels mimic the effects of secondary collectors along with 60 microchannels with the help of porous medium approximation. The scalability of the ROM helps to simplify and model the characteristics of secondary collectors and 60 microchannels to a single cylindrical duct. Collector height plays a prominent role in the collector performance by controlling the maldistribution. Five different primary collector configurations with five different heights were selected to investigate the primary collector performance. Primary collector inlet mass flow is kept constant, and the collector height is varied. A single hot-inlet side mass flow with pressure outlet and free-slip boundary condition on the cylindrical walls. No-slip boundary condition is implemented on the first collector walls. The inlet and outlet walls were extruded with slip walls to avoid reverse flows.

Figure 11a, shows mass flow deviation for five different collector heights, calculated based on the secondary collector performance using Eq. (8). Lower the height, the higher the mass flow deviation. Anbumeenakshi and Thansekhar [45] pointed out that at higher Reynolds numbers, the strong interaction of the high-velocity jet flow along the slanting surface of the trapezoidal collectors at the entrance creates an intensified vortex, lowering the static pressure in the upstream of the header. Thus the microchannels near the primary collector inlets are badly distributed. As the height increase, the intensity of the powerful 

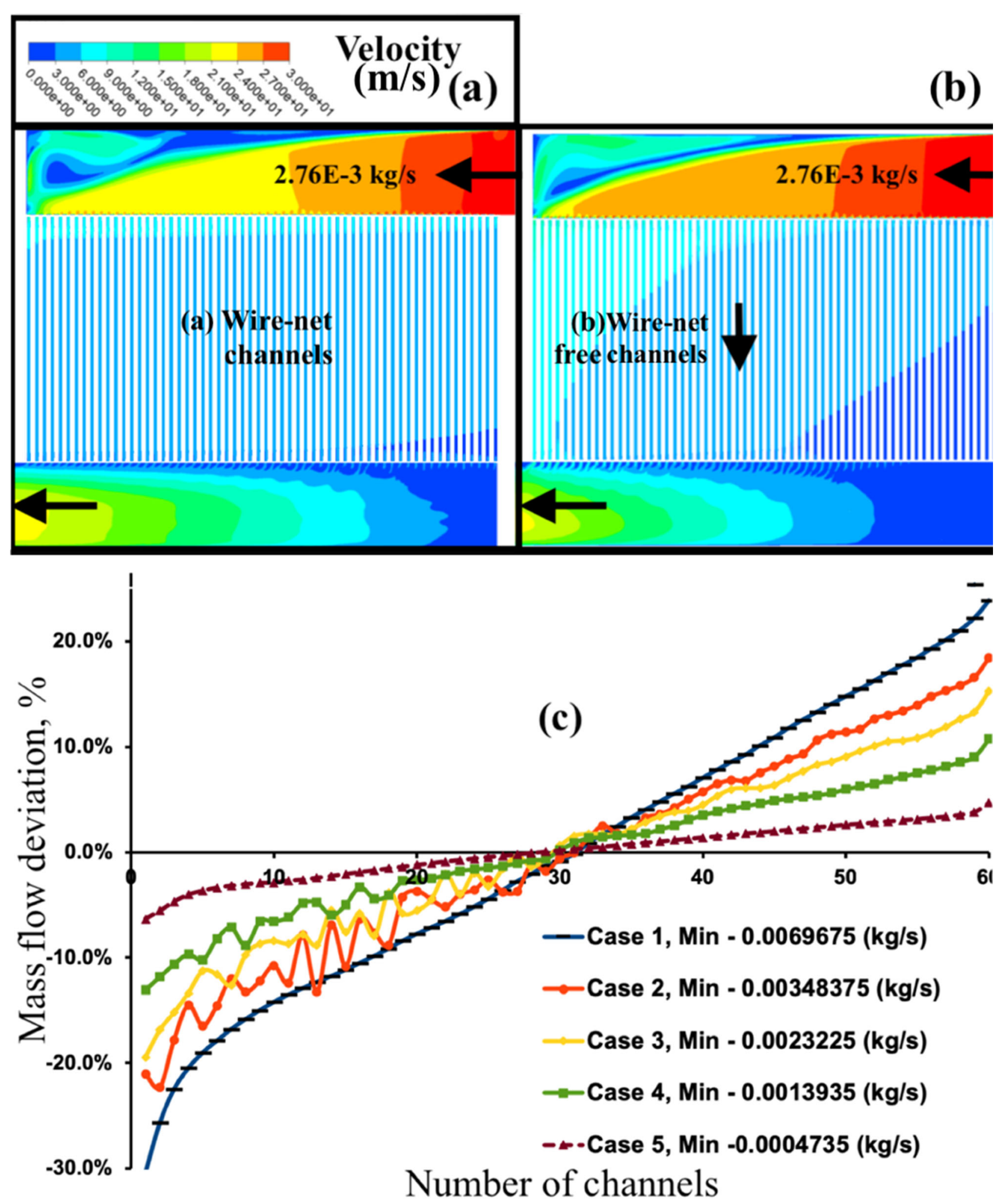

Figure 10. Secondary collector velocity contour for wire-net microchannels (a), for free microchannels (b), and mass flow deviation from the ideal $\mathrm{CHT}$ inlet mass flow (c).

interaction of the high-velocity jet flow decreases, and thereby, the collector performance increases.

Figure $11 b, c$ show the velocity contour for maximum and minimum heights. There are strong recirculation zones near the exit and strong velocity gradients near the inlet of the secondary collectors. The intensity of velocity gradients is strong at smaller heights compared to the maximum height. The $50 \mathrm{~mm}$ 

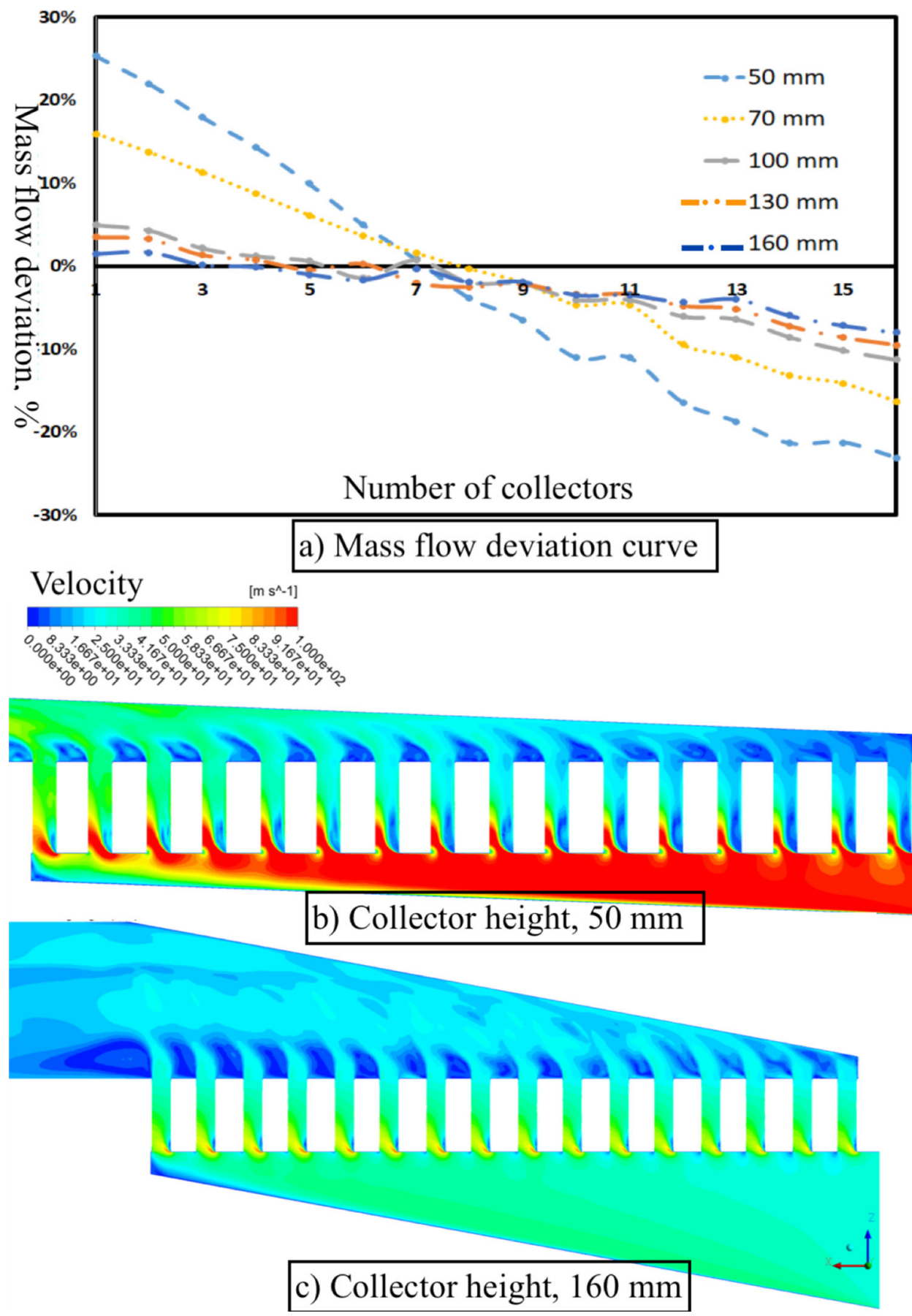

Figure 11. Mass flow deviation from the secondary collector inlet mass flow (a), primary collector velocity contour for collector height $=50 \mathrm{~mm}(\mathrm{~b})$, and for collector height $=160 \mathrm{~mm}$ (c).

Table 3. Overall wire-net compact heat exchanger performance for BC operating conditions.

\begin{tabular}{lcc}
\hline $\mathrm{m}_{\text {co }}(\mathrm{kg} / \mathrm{s})$ & Pressure drop, $(\%)$ & Efficiency, $(\%)$ \\
\hline 0.0069675 & 7.42 & 81.25 \\
0.0034823 & 2.55 & 86.64 \\
0.0023225 & 1.41 & 88.07 \\
0.0001393 & 0.70 & 89.01 \\
0.0000473 & 0.19 & 84.30 \\
\hline
\end{tabular}

height channels have the worst distribution pattern, and on the contrary, the $160 \mathrm{~mm}$ case is affected the least. The collector configuration at $50 \mathrm{~mm}$ has high momentum fluid (relative to other cases), which results in static pressure rise in the collectors and thereby by maldistribution. The relative difference in mass flow deviation for heights greater than $100 \mathrm{~mm}$ is relatively less. In conclusion, the primary collector with $100 \mathrm{~mm}$ is found to be the optimum. 
1) Compressor

2) Thermocuple and pressure sensor

3) Volumetric flow meter

4) Air heater

5 -8) Thermocouple

9) Volumetric flow meter

10) Exhaust

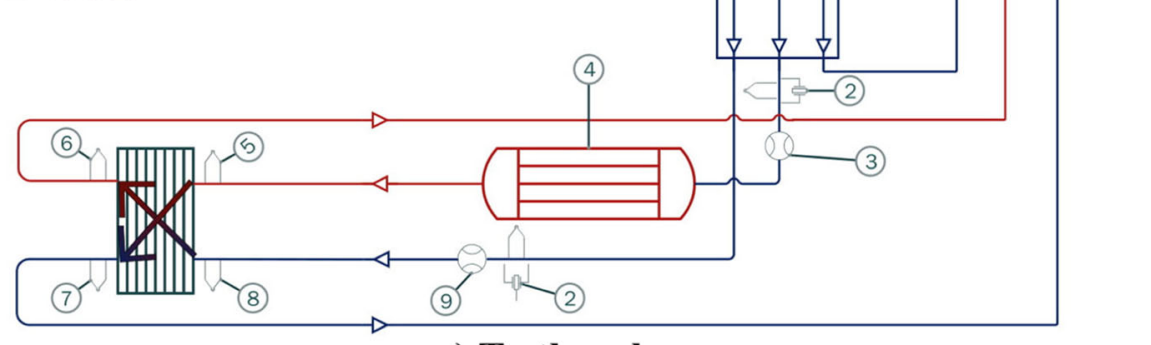

a) Testbench

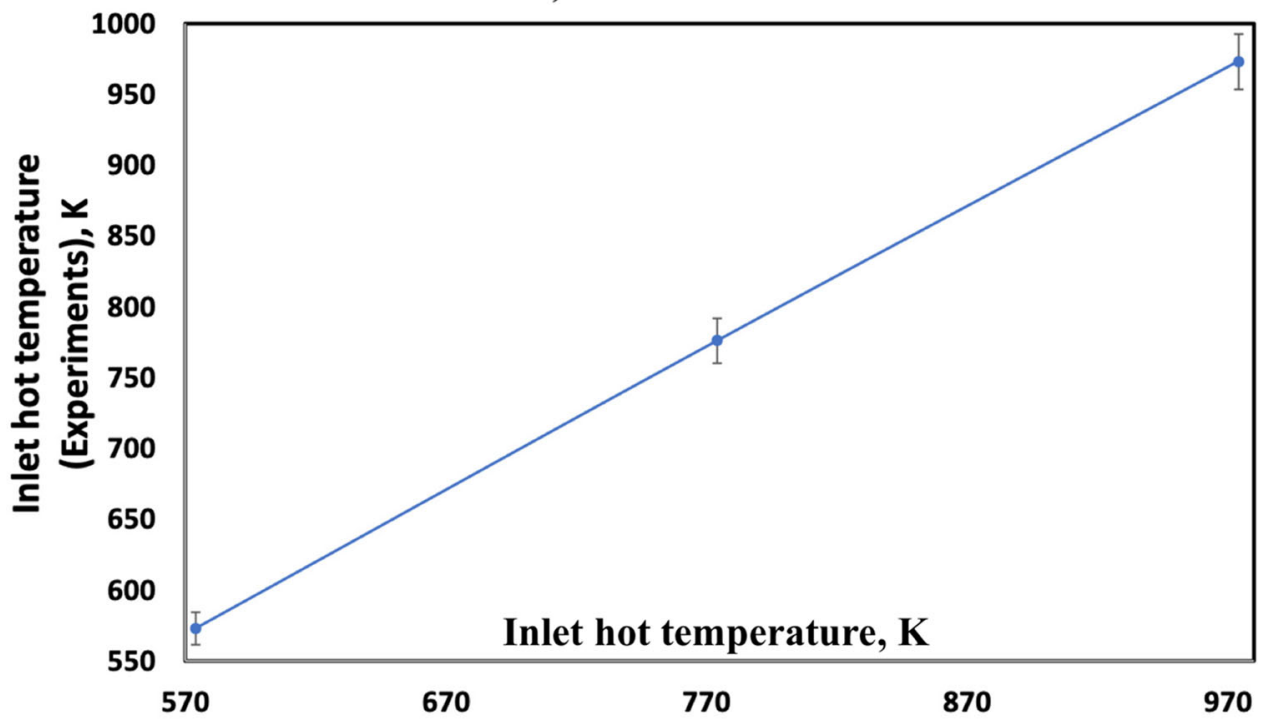

b) Uncertainity in temperature measurements

Figure 12. Scheme of test bench (a) and uncertainty analysis (b).

\section{High-temperature testing}

\section{Experimental setup}

A Brazed heat exchanger configuration with two hot and cold collector inlets with 120 microchannels were selected for high-temperature heat exchanger testing. The microchannels and the secondary collectors remains the same for both numerical and experimental analysis, while the primary collector design is different. The experimental setup mainly consists of a heat exchanger and a preheater. The preheater heats the flow to the desired temperature before accessing the hot-inlet. Hot and cold side temperatures and pressures were measured at pressure taps at the entrances and outlets of the heat exchanger with enough straight run to ensure accurate measurements. Mass flow meters are installed before the hot and cold inlets. Thermocouples were placed at collector inlets and out- lets of the heat exchanger model. However, the effect of radiation to the outside was not taken into consideration because of the excellent insulation ( $5 \mathrm{~cm}$-thick special incombustible woolen layer) to the ambient. The layer insulates the heat exchanger as well as pipes and the air heater.

The objective of the high-temperature experimental testing is to characterize the collector performance and compare the thermal effectiveness relative to the ROM effectiveness. A general scheme of the test bench is depicted in Figure 12a. The temperature is measured with type $\mathrm{K}$ thermocouples, with a standard limit of uncertainty equal to $2.2^{\circ} \mathrm{C}$. Additionally, measurement of volumetric flow is taken from a GASVIEW device, which can measure volumetric flow in a range of $167 \mathrm{~L} / \mathrm{min}$ to $850 \mathrm{~L} / \mathrm{min}$, with an accuracy of $\pm 3 \%$ FS. Moreover, effectiveness is calculated using 
Eq. (2). Furthermore, pressure sensors were installed in the primary collectors that feed the mass flow to the secondary collectors and then to the microchannels. The temperature was analyzed for 10 minutes and the uncertainty in temperature measurements for experimental hot inlet temperatures (based on the inlet conditions) is depicted in Figure 12b. The instrumental uncertainties are shown in Table 4.

Table 4. Characteristics and accuracy of instrumentation.

\begin{tabular}{llc}
\hline Instrument & \multicolumn{1}{c}{ Range (0-FS) } & Accuracy \\
\hline Vol. Flowmeter & $167 \mathrm{~L} / \mathrm{min}-850 \mathrm{~L} / \mathrm{min}$ & $\pm 3 \% \mathrm{FS}$ \\
Pressure sensor & $0-2 \mathrm{BAR}$ & $\pm 0.25 \% \mathrm{FS}$ \\
Thermocouples & $-200^{\circ} \mathrm{C}$ to $1,250^{\circ} \mathrm{C}$ & $2.2^{\circ} \mathrm{C}$ \\
\hline
\end{tabular}

Afterwards, LABVIEW V2017 is used to display and save the data in real time.

\section{Conjugate heat transfer model and experiments}

In order to investigate the pressure drop dependency on temperature, the primary collector was supplied with a mass flow of $8 \mathrm{~g} / \mathrm{s}$. Note that the primary collectors design for experimental testing is not the same as of numerical model. The preheater preheats the air to desired temperatures step by step to ensure steady mass flow. As the mass flow increases, the temperature influences the density and thereby, the velocity increases, and through the pressure losses increase as well. Figure 13a
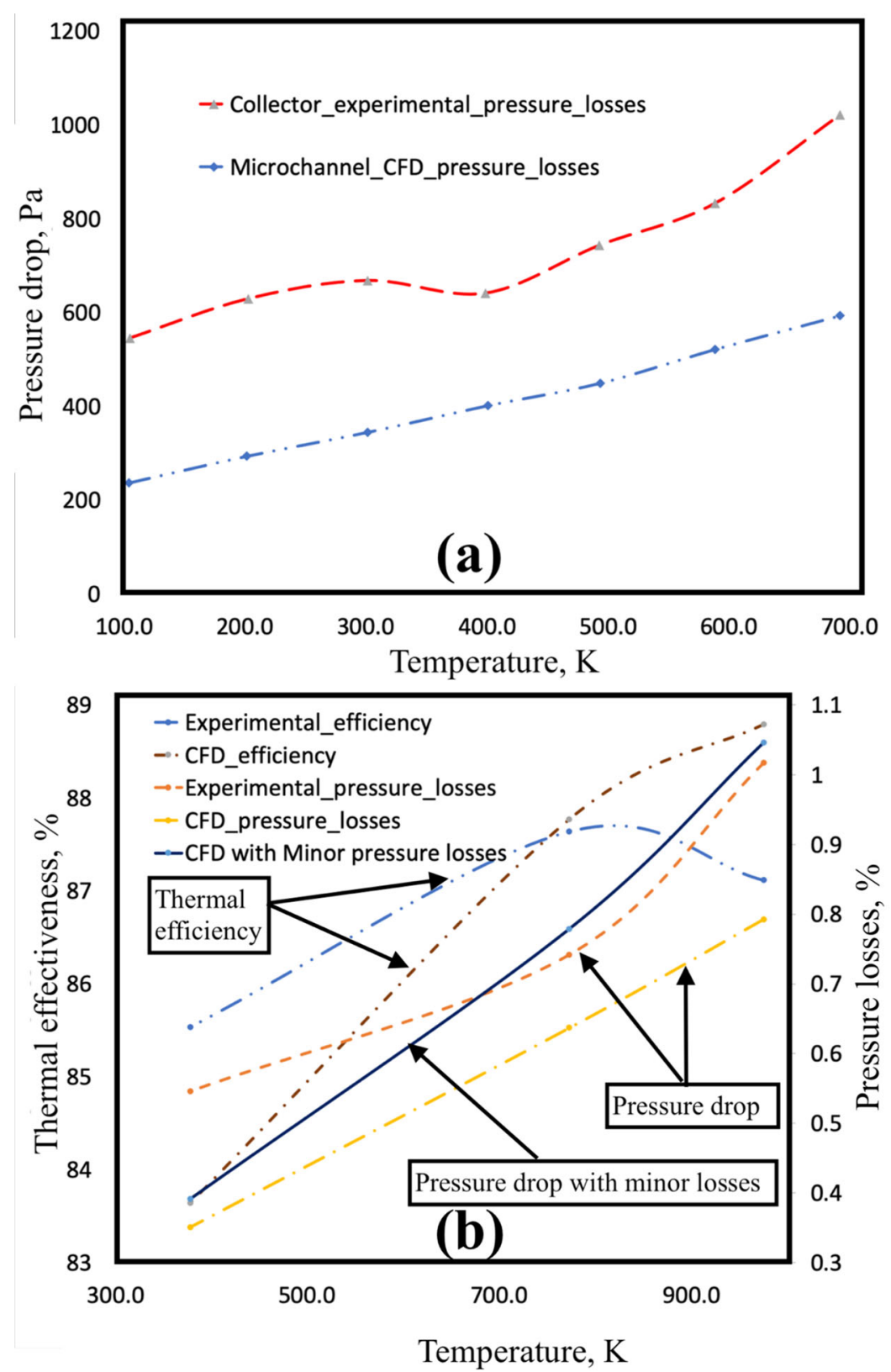

Figure 13. Comparison plot between CFD and experiments for microchannel performance (a) and overall heat exchanger performance (b) for various temperatures. 
shows the pressure drop increase with the temperature increase. The microchannel pressure losses refer to the pressure losses from the CHT analysis, and the experimental collector pressure losses include both primary and secondary collector pressure losses. The collector pressure loss is determined using Eq. (4). The pressure loss difference between CFD and experiments for all temperatures is around $40-55 \%$ of the microchannel pressure losses. The results coincide with the findings from the ROM. Based on the heat exchanger arrangement, the collector's contribution toward heat recovery is small ( $<10 \%$ of the overall thermal effectiveness). Thus, it is not worth loosing high-pressure/power losses in the collectors.

\section{Reduced order model and experiments}

The primary collector was supplied with a mass flow of $6 \mathrm{~g} / \mathrm{s}$. Note that the primary collectors design for experimental testing is not similar to the trapezoidal collectors. Figure 13b shows the thermal effectiveness and pressure losses obtained at different temperatures. The thermal effectiveness is plotted for various temperatures (mass flow $=6 \mathrm{~g} / \mathrm{s}$ ) on the primary $y$-axis, and the pressure losses were plotted on the secondary $y$-axis for various temperatures. The upper and lower scale of the primary y-axis (thermal effectiveness) is in between 81 and $89 \%$. The thermal effectiveness differences between the CFD and the experiment is in the range of 0.3 to $4.4 \%$. The acceptable range for the thermocouple measurement is depicted in Figure 11b. Moreover, the difference between thermal effectiveness between CFD and experiments is relatively low $\left(20-30 \mathrm{~K}\right.$, where the $\left.\mathrm{T}_{\text {in }}^{\mathrm{h}}=973 \mathrm{~K}\right)$.

The relative small temperature drop mainly arises due to axial conductivity losses of the thick plates which hold the heat exchanger block which was ignored during the reduced order modeling. For ROM, the collector walls were fully adiabatic, and there is no thermal losses to the surroundings. In conclusion, the microchannel CHT model predicts the thermal efficiency with reasonable accuracy $(<4.4 \%)$.

The experimental pressure losses are relatively high due to the minor pressure losses that arise from small primary collectors. The preheated mass flow enters the primary collector, and the primary collector distributes the flow to the secondary collectors separately. At very low temperatures, the accuracy of the pressure sensor is relatively low for smaller pressure drops. At the exit of the secondary collector, there is a strong unsteadiness/recirculation zones, which makes it complicated to place the pressure sensors near the exit of the secondary collector. This was investigated numerically and found a strong recirculation zone near the downstream of the collector outlet. Rehman et al. [46] examined minor head losses directly using standard experimental empirical correlations and found it accurate to compare the results with experiments. The minor pressure losses occurring in pipe flows/fittings were extensively studied and a standard methodology proposed by Munson et al. [47] is utilized to calculate the minor pressure losses,

$$
\Delta \mathrm{P}=\mathrm{K}_{\text {effec }} 0.5 \rho \mathrm{U}^{2}
$$

The minor pressure losses were calculated using Eq. (9) were added to the CFD pressure losses for three different temperatures with specific mass flows and depicted in Figure 13b. The discrepancy between CFD and experimental pressure losses is decreased and thereby, ROM is validated.

\section{Conclusions}

Shifting the critical Reynolds number to lower Reynolds number enhances the CHE performance. The metallic wire-net yields high efficiency but significant pressure losses compared to S-shape microchannels. Replacing the metallic wire-net structures by S-shaped fins enhances the compact heat exchanger performance in terms of pressure losses. While comparing the relative performance (thermal efficiency and pressure losses) for a particular mass flow/area, S-shaped fins are better. Thermal efficiency reaches its maximum at a particular optimum mass flow, and the thermal efficiency pattern remains the same for both perturbators.

The strong counter-rotating vortices near the wire net intersections mix the centrally convected non-disturbed mass flow. The wire-net geometry suppresses the separation and reduces the size of flow detachment zones lowering the pressure losses with an enhanced heat transfer. The turbulent Reynolds stress is directly correlated with maximum heat transfer zones (locally). Furthermore, the S-shaped perturbators induced strong wall-normal velocity fluctuations and enhanced the heat transfer. The particular anisotropic turbulent production term coincided with the maximum wall heat flux.

ROM conclusively determined the collector mass flow distribution and thereby the overall heat exchanger performance for the wire-net CHE model. As the microchannel pressure loss increases, the flow distribution is more uniform, and there is an active recirculation zone in the cylindrical collectors that influence the collector performance. Higher the primary collector height, lower the maldistribution, and thereby, overall thermal and hydraulic performance is 
enhanced. There is an optimum height where the pressure loss is saturated, and the non-uniformity in maldistribution is relatively less (for different primary collector heights).

Experimental results and CFD results are in good agreement regarding thermal efficiency and pressure losses (with minor pressure losses). Experimental thermal efficiency can be improved by changing the insulating material or with thicker insulation, and thereby, reducing heat losses to the environment. However, the experimental pressure losses are higher than the numerical model due to the minor pressure losses created by the small primary collectors. A good agreement between CFD and experiments was observed when the primary collector pressure losses were added as minor pressure losses to the CFD pressure losses.

\section{Funding}

This ITN Research Project MIGRATE (www.migrate2015.eu) is supported by European Community H2020 Framework under the Grant Agreement No. 643095. The research of MITIS has been funded by grants Nanocogen + and Nanocogen +2 from DGO4 and DGO6 directorates of Wallonia.

\section{Notes on contributors}

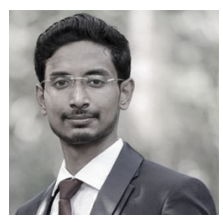

Jojomon Joseph is currently working as an Early Stage Researcher in Mitis, Belgium and is a Ph.D. student in the Institute of Microstructure Technology of Karlsruhe Institute of Technology, Germany. $\mathrm{He}$ received his M.Sc. in turbulence, a joint master's program by Ecole Centrale de Lille, Ecole Nationale Supérieure de Mécanique et d'Aérotechnique de Poitiers and Ecole Nationale Supérieure d'Ingénieurs de Poitiers, France. His research is focused on numerical modeling and experimental investigation of turbulence influence on heat transfer characteristics for low Reynolds number flows. His research also includes microfabrication of microchannels using 3D printing techniques. $\mathrm{He}$ is also a part of MIGRATE (MIniaturized Gas flow foR Applications with enhanced Thermal Effects), Innovative Training Network.

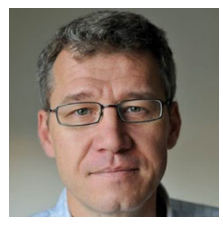

Michel Delanaye is the founder of MITIS $\mathrm{SA}$, a startup company located in Liège (Belgium) specialized in the development of clean distributed small cogeneration systems. He holds a Ph.D. in Mechanical Engineering from the University of Liège in the area of computational fluid dynamics with emphasis on aerodynamics. He was awarded a Fulbright grant, NATO postdoctoral fellowship and US National Research Council Associate position at NASA Ames Research Council from 1996 to 1999. $\mathrm{He}$ had positions at NUMECA Int as $\mathrm{R} \& \mathrm{D}$ engineer and general manager at Cenaero. $\mathrm{He}$ is also the founder of GeonX SA, a startup company developing software in the field of virtual manufacturing, acquired in 2017 by General Electric.

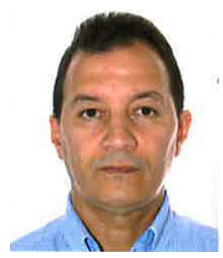

Rabia Nacereddine is currently working as a Research Engineer in Mitis, Belgium. He completed his Post-Doc in 2012, on optimization of the heat exchanger performance from Ecole des Mines de Douai, France. He completed his Ph.D. in fluid mechanics and heat transfer from Université Joseph Fourier-Grenoble, France (2007). He worked on turbulence generations mechanisms for his $\mathrm{PhD}$. His research is on improving the heat transfer by passives methods, using CFD approach. Apart from this, he also deals with the design of the micro-CHP system: the design of the heat exchanger, the flameless combustion chamber, the micro-compressor, and the micro-turbine.

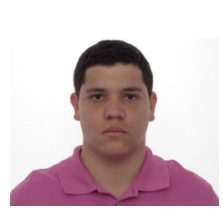

Andres Giraldo is currently working as a design engineer at MITIS SA in Belgium. He received his M.Sc. in turbomachines at the Royal Institute of Technology in Sweden and the University of Liege in Belgium. His work is focused on the development of micro-gas turbines for residential applications.

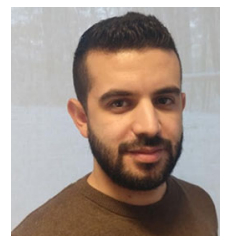

Mehdi Rouabah is currently working as research engineer in Mitis SA Belgium and enrolled as a Ph.D. student at the Free University of Brussels, Belgium. He received his master's degree in fluids and energetics applications from the University of Khemis Miliana, Algeria. He worked as a research engineer in FIMA (Laboratory of industrial fluids, measurements and applications) after he joined a consultancy company specializing on hospital construction. Currently, he works on the design, development, and optimization of flameless combustion chambers for micro CHP applications (validation of numerical studies by experimental testing). In addition, he also works on advanced brazing techniques to develop cost-effective heat exchangers

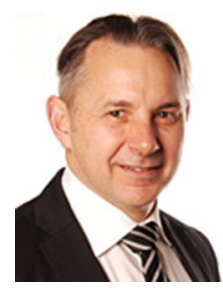

Jan G. Korvink received the M.Sc. degree in mechanical engineering (specializing in computational mechanics) from the University of Cape Town, South Africa, in 1987, and the Ph.D. degree from ETH Zurich, Switzerland, in 1993. He joined the University of Freiburg, Germany, as a 
Full Professor of Microsystems Engineering, where he codirected the Freiburg Institute for Advanced Studies. In 2015, he joined the Karlsruhe Institute of Technology, where besides directing the Institute of Microstructure Technology, he also acts as a Speaker of the Helmholtz Research Program in the Science and Technology of Nanosystems. He is also a co-founder of two successful startup companies. He has authored or coauthored more than 200 technical publications in the broad area of microsystems. His research interests include the development of ultra-low-cost micro manufacturing methods, micro system applications in the area of magnetic resonance imaging, and the design and simulation of micro- and nanosystems. $\mathrm{He}$ was a recipient of the Red Dot Design Concept Award in 2011 and the European Research Council Advanced Grant in the area of micro NMR metabolomics for the nematode C. elegans. He is a Founding Editor of the Advanced Micro and Nanosystems.

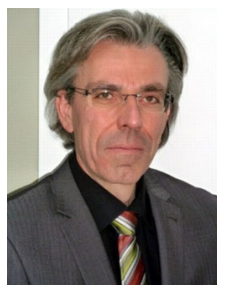

Juergen J. Brandner is currently head of a research group at the Institute of Microstructure Technology of Karlsruhe Institute of Technology (KIT), Germany. $\mathrm{He}$ is dealing with design and manufacturing as well as thermal management of microscale devices. Aside, development and integration of miniaturized sensors into microfluidic devices and NMR/MRI applications to thermal, chemical, and biochemical processes in micro devices are in his interests. After studies in Chemistry, he obtained a diploma in Electrical Engineering, and an Engineering Doctorate in Mechanical Engineering, both from KIT. He also holds a Habilitation and Professorship (hon) in Micro Process Engineering from Technical University of Dresden. He is Lecturer at KIT and coordinating the Marie-Curie-ITN "MIGRATE."

\section{References}

[1] M. Hinnells, "Combined heat and power in industry and buildings," Energy Policy, vol. 36, no. 12, pp. 4522-4526, Dec. 2008. DOI: 10.1016/j.enpol.2008.09. 018.

[2] M. A. Rosen, M. N. Le, and I. Dincer, "Efficiency analysis of a cogeneration and district energy system," Appl. Therm. Eng., vol. 25, no. 1, pp. 147-159, Jan. 2005. DOI: 10.1016/j.applthermaleng.2004.05. 008 .

[3] M. Delanaye et al., "Development of a recuperated flameless combustor for an inverted Bryton cycle microturbine used in residential micro-CHP," presented at the ASME. Turbo Expo: Power for Land, Sea, and Air, vol. 4B: Charlotte, NC, USA, June 26-30, 2017.

[4] C. F. McDonald, "Low-cost compact primary surface recuperator concept for microturbines," Appl. Therm. Eng., vol. 20, no. 5, pp. 471-497, Apr. 2000. DOI: 10.1016/S1359-4311(99)00033-2.

[5] R. K. Shah, "Advances in science and technology of compact heat exchangers," Heat Transf. Eng., vol. 27, no. 5, pp. 3-22, Dec. 2006. DOI: 10.1080/ 01457630600559462.

[6] S. S. Mehendale, A. M. Jacobi, and R. K. Shah, "Fluid flow and heat transfer at micro- and mesoscales with application to heat exchanger design," ASME Appl. Mech. Rev., vol. 53, no. 7, pp. 175-193, 2000. DOI: $10.1115 / 1.3097347$.

[7] S. Kandlikar, J. Shailesh, and T. Shurong, "Effect of surface roughness on heat transfer and fluid flow characteristics at low Reynolds numbers in small diameter tubes," Heat Transf. Eng., vol. 24, no. 3, pp. 4-16, 2003. DOI: 10.1080/01457630304069.

[8] B. Sunden, Advanced Computational Methods in Heat Transfer IX, 2nd ed. Southampton, UK: WIT Press, 2006.

[9] H. Nakamura, T. Igarashi, and T. Tsutsui, "Local heat transfer around a wall-mounted cube in the turbulent boundary layer," Int. J. Heat Mass Transf., vol. 44, no. 18 , pp. 3385-3395, Sep. 2001. DOI: 10. 1016/S0017-9310(01)00009-6.

[10] K. Hanjalic, E. R. Meinders, and R. J. Martinuzzi, "Experimental study of the local convection heat transfer from a wall-mounted cube in turbulent channel flow," J. Heat Transf., vol. 3, no. 17, pp. 564-573, 1999. DOI: 10.1115/1.2826017.

[11] M. Fiebig, "Vortex generators for compact heat transfer exchangers," J. Enhanc. Heat Transf., vol. 2, no. 1-2, pp. 43-61, 1995. DOI: 10.1615/ JEnhHeatTransf.v2.i1-2.60.

[12] D. P. DeWitt, and F. P. Incropera, Introduction to Heat Transfer. Hoboken, NJ, USA: John Wiley and Sons, 1996.

[13] M. Fiebig, "Vortices, generators and heat transfer," Chem. Eng. Res. Des., vol. 2, no. 263, pp. 108-123, Feb. 1998. DOI: 10.1205/026387698524686.

[14] T. R. Johnson, and P. N. Joubert, "The influence of vortex generators on the drag and heat transfer from a circular cylinder normal to an airstream," J. Heat Transf., vol. 91, no. 1, pp. 91-99, Aug. 1969. DOI: 10.1115/1.3580126.

[15] L. Luo, C. Pistoresi, and Y. Fan, "Numerical study on the improvement of flow distribution uniformity among parallel mini-channels," Chem. Eng. Process. Process Intensif., vol. 95, no. 13, pp. 63-71, Jul. 2015. DOI: $10.1016 /$ j.cep.2015.05.014.

[16] A. Siddique, B. J. Medhi, A. Agrawal, A. Singh, and S. K. Saha, "Design of a collector shape for uniform flow distribution in microchannels," J. Micromech. Microeng., vol. 27, no. 13, pp. 26-50, 2017. DOI: 10 . 1088/1361-6439/aa73eb.

[17] Y. Yang, I. Gerken, J. J. Brandner, and G. L. Morini, "Design and experimental investigation of a gas-togas counter-flow micro heat exchanger," Exp. Heat Transf., vol. 27, no. 4, pp. 340-359, Sep. 2014. DOI: 10.1080/08916152.2013.849179.

[18] Y. Yang, "Experimental and numerical analysis of gas forced convection through microtubes and micro heat exchangers", Ph.D. dissertation, Dept. Ingegneria Energetica, Nucleare e del Controllo Ambientale, UNIBO, Italy, 2013.

[19] S. Salehi, H. Afshin, and B. Farhanieh, "Numerical investigation of the inlet baffle, header geometry, 
and triangular fins effects on plate-fin heat exchangers performance," Heat Transf. Eng., vol. 36, no. 16, pp. 1397-1408, Sep. 2015. DOI: 10.1080/01457632. 2015.1003720 .

[20] H. Yang, J. Wen, X. Gu, K. Li, S. Wang, and Y. Li, "Improvements on flow distribution and heat transfer performance of plate-fin heat exchangers by Qusai-S type header configuration," Heat Transf. Eng., vol. 38, no. 18, pp. 1547-1560, Dec. 2017. DOI: 10.1080/01457632.2016.1262719.

[21] V. M. Siva, A. Pattamatta, and S. K. Das, "Effect of flow maldistribution on the thermal performance of parallel microchannel cooling systems," Int. J. Heat Mass Transf., vol. 73, pp. 424-430, Jun. 2014. DOI: 10.1016/j.ijheatmasstransfer.2014.02.017.

[22] P. Chu, L. Yong-Gang, Y. He, and R. Li, "Design and optimization of heat exchangers with helical baffles," Chem. Eng. Sci., vol. 63, no. 17, pp. 4386-4395, 2008. DOI: 10.1016/j.ces.2008.05.044.

[23] Y. Li, J. Wen, A. Zhou, K. Zhang, and J. Wang, "PIV experimental investigation of entrance configuration on flow maldistribution in plate-fin heat exchanger," Cryogenics, vol. 46, no. 1, pp. 37-48, 2006. DOI: 10.1016/j.cryogenics.2005.10.010.

[24] V. V. Dharaiya, and S. G. Kandlikar, "Evaluation of a tapered header configuration to reduce flow maldistribution in minichannels and microchannels", presented at the Proceedings of the ASME 7th International Conference on Nanochannels, Microchannels and Mini-channels, Pohang, South Korea, Jun. 22-24, 2009. DOI: 10.1115/ ICNMM2009-82288.

[25] J. K. Tong, E. M. Sparrow, and J. P. Abraham, "Attainment of flowrate uniformity in the channels that link a distribution manifold to a collection manifold," ASME J. Fluids Eng., vol. 129, no. 9, pp. 1186-1192, 2007. DOI: 10.1115/1.2754319.

[26] M. Hoffmann, J. Walmsley, and V. Neale, "Flow profiles on the fin side of a plate fin-and-tube heat exchanger experiencing gross flow maldistribution", presented at the Proceedings of 7 th world conference, Experimental Heat Transfer, Fluid Mechanics and Thermodynamics, Krakow, Poland, Jun. 28-Jul. 3, 2009.

[27] C. B. Sobhan, and S. V. Garimella, "A comparative analysis of studies on heat transfer and fluid flow in microchannels," Microscale Thermophys. Eng., vol. 5, no. 4, pp. 293-311, 2001. DOI: 10.1080/ 10893950152646759.

[28] A. Barbaros Cetin, M. Haluk, and K. G. Guler, "Computational modelling of vehicle radiators using porous medium approach," Des. Exp. Simul., vol. 2, no. 21, pp. 243-262, 2017. DOI: 10.5772/6628.

[29] L. Z. Zhang, "Flow maldistribution and thermal performance deterioration in a cross-flow air to air heat exchanger with plate-fin cores," Int. J. Heat Mass Transf., vol. 52, no. 19-20, pp. 4500-4509, 2009. DOI: 10.1016/j.ijheatmasstransfer.2009.03.049.

[30] W. Wang, J. Guo, S. Zhang, J. Yang, X. Ding, and X. Zhan, "Numerical study on hydrodynamic characteristics of plate-fin heat exchanger using porous media approach," Comput. Chem. Eng., vol. 61, pp. 30-37, Feb. 2014. DOI: 10.1016/j.compchemeng.2013.10.010.

[31] J. Joseph et al., "Numerical and experimental investigation of a wire-net compact heat exchanger performance for high-temperature applications," Appl. Therm. Eng., vol. 154, pp. 208-216, May 2019. DOI: 10.1016/j.applthermaleng.2019.03.046.

[32] J. Joseph, M. Delanaye, R. Nacereddine, J. J. Brandner, and J. G. Korvink, "Advanced numerical methodology to analyze high-temperature wire-net compact heat exchangers for a micro-combined heat and power system application," Heat Transf. Eng., vol. 41, no. 11. DOI: 10.1080/01457632.2019.1589984.

[33] N. Tsuzuki, M. Utamura, and T. L. Ngo, "Nusselt number correlations for a microchannel heat exchanger hot water supplier with S-shaped fins," Appl. Therm. Eng., vol. 29, no. 16, pp. 3299-3308, Nov. 2009. DOI: 10.1016/j.applthermaleng.2009.05.004.

[34] D. Rehman, J. Joseph, G. L. Morini, M. Delanaye, and J. Brandner, "A porous media model for a double-layered gas-to-gas micro heat exchanger operating in laminar flow regime," presented at the UIT Heat Transfer Conference, Padova, Italy, Jun. 24-26, 2019.

[35] K. Gersten, HermannSchlichting, Boundary-Layer Theory, 9th ed. Berlin, Germany: Springer-Verlag, 2017.

[36] Bodenschatz Group, "Grid turbulence, turbulence generation and manipulation", Germany, [Online]. Available: http://www.lfpn.ds.mpg.de/turbulence/generation.html. Accessed: May 21, 2019.

[37] G. Y. Lai, High-Temperature Corrosion and Materials Applications, 2nd ed. Cambridge, MA: Woodhead Publishing, 2017.

[38] S. Pope, Turbulent Flows. Cambridge, UK: Cambridge University Press, 2000

[39] E. R. Meinders, T. H. Van Der Meer, and K. Hanjalic, "Local convective heat transfer from an array of wall-mounted cubes," Int. J. Heat Mass Transf., vol. 41, no. 2, pp. 335-346, Jan. 1998. DOI: 10.1016/S0017-9310(97)00148-8.

[40] R. Manceau, Industrial Codes for CFD, International Masters in Turbulence, 1st ed. Pau, France: Applied Mathematics Department, Inria-Cagire Group. CNRS-University of Pau, 2017 [Online]. Available: http://remimanceau.gforge.inria.fr/Publis/PDF/ IndustrialCodesForCFD.pdf. Accessed: May. 23, 2019.

[41] F. Afroz, and M. A. R. Sharif, "Numerical analysis of the flow separation and adverse pressure gradient in laminar boundary layer over a flat plate due to a rotating cylinder in the vicinity," Fluid Dyn. Res., vol. 50, no. 2, pp. 1-46, Jan. 2018. DOI: 10.1088/ 1873-7005/aa9629.

[42] J. Moore, J. G. Moore, S. P. Heckel, and R. Ballesteros, "Reynolds stresses and dissipation mechanisms in a turbine tip leakage vortex," presented at the ASME Turbo Expo: Power for Land, Sea, and Air, vol. 5: Manufacturing Materials and Metallurgy; Ceramics; Structures and Dynamics; Controls, Diagnostics and Instrumentation, The Hague, Netherlands, Jun. 13-16, 1994. DOI: 10.1115/94-GT267. 
[43] J. Wallace, H. Eckelmann, and R. Brodkey, "The wall region in turbulent shear flow," J. Fluid Mech., vol. 54, no. 1, pp. 39-48, 1972. DOI: 10.1017/ S0022112072000515.

[44] J. Teng, J. Chu, M. Liu, C. Wang, and R. Greif, "Investigation of the flow mal-distribution in microchannels," presented at the ASME 2003 International Mechanical Engineering Congress and Exposition, Microelectromechanical System, Washington, DC, USA, Nov. 15-21, 2003. DOI: 10.1115/IMECE200341323.

[45] C. Anbumeenakshi, and M. R. Thansekhar, "Experimental investigation of header shape and inlet configuration on flow maldistribution in microchannel," Exp. Therm. Fluid Sci., vol. 75, pp. 156-161, Jul. 2016. DOI: 10.1016/j.expthermflusci. 2016.02.004.

[46] D. Rehman, G. L. Morini, and C. Hong, "A comparison of data reduction methods for average friction factor calculation of adiabatic gas flows in microchannels," Micromachines, vol. 171, no. 3, pp. 1-19, 2019. DOI: $10.3390 / \mathrm{mi} 10030171$.

[47] B. R. Munson, D. F. Young, T. H. Okiishi, and W. W. Huebsch, Fundamentals of Fluid Mechanics, 6th ed. Hoboken, NJ, USA: John Willey and Sons Inc., 2009. 